\title{
Quantum chemical calculations and spectroscopic measurements of spectroscopic and thermodynamic properties of given uranyl complexes in aqueous solutions with possible environmental and industrial applications
}

\author{
Jakub Višňák ${ }^{1,2,3}$, Lukáš Sobek ${ }^{1,3}$ \\ ${ }^{1}$ Dep. of Nuclear Chemistry, FNSPE, Czech Technical University, Břehová 7, 11519 Prague 1, Czech Rep. \\ ${ }^{2}$ Dep. of Chemical Physics and OpticsCharles University, Ke Karlovu 3, 12116 Prague 2, Czech Rep. \\ ${ }^{3} J$. Heyrovský Institute of Physical Chemistry, Dolejškova 2155/3, 18223 Prague 8, Czech Rep.
}

\begin{abstract}
A brief introduction into computational methodology and preliminary results for spectroscopic (excitation energies, vibrational frequencies in ground and excited electronic states) and thermodynamic (stability constants, standard enthalpies and entropies of complexation reactions) properties of some 1:1, 1:2 and 1:3 uranyl sulphato- and selenato- complexes in aqueos solutions will be given. The relativistic effects are included via Effective Core Potential (ECP), electron correlation via (TD)DFT/B3LYP (dispersion interaction corrected) and solvation is described via explicit inclusion of one hydration sphere beyond the coordinated water molecules. We acknowledge limits of this approximate description - more accurate calculations (ranging from semi-phenomenological two-component spin-orbit coupling up to four-component Dirac-Coulomb-Breit hamiltonian) and Molecular Dynamics simulations are in preparation. The computational results are compared with the experimental results from Time-resolved Laser-induced Fluorescence Spectroscopy (TRLFS) and UV-VIS spectroscopic studies (including our original experimental research on this topic). In case of the TRLFS and UV-VIS speciation studies, the problem of complex solution spectra decomposition into individual components is ill-conditioned and hints from theoretical chemistry could be very important. Qualitative agreement between our quantum chemical calculations of the spectroscopic properties and experimental data was achieved. Possible applications for geochemical modelling (e.g. safety studies of nuclear waste repositories, modelling of a future mining site) and analytical chemical studies (including natural samples) are discussed.
\end{abstract}

\section{Motivation}

Uranium and, in particular, soluable uranyl complex compounds are of great importance for both nuclear energetics and environmental chemistry.

Thermodynamic properties of several uranyl complexes (stability constants, $\beta^{\circ}$, standard complexation enthalpies $\Delta H^{\circ}$, entropies $\Delta S^{\circ}$ and the interaction parameters $\varepsilon(i, j)$ (from the Specific Ion Interaction Theory [70-72])) are important input parameters for geochemical modelling studies of various systems ranging from homogenous nuclear reactors to radioactive waste repositories (RWR) or uranium mining sites.

Spectroscopic properties are important for chemical analysis/detection of the previously mentioned complexes. This include use in natural waters chemical analysis (near the mining sites, RWRs or in environment in general). We were concerned in UV-VIS spectrophotometry and TimeResolved Laser-Induced Fluorescence Spectroscopy (TRLFS) [1].

The above mentioned thermodynamic stability constants $\beta^{\circ}$ are assigned to chemical reactions

$$
\begin{aligned}
& \mathrm{UO}_{2}\left(\mathrm{H}_{2} \mathrm{O}\right)_{5}^{2+}+m X O_{p}^{2-} \\
& +\mathrm{fH}_{2} \mathrm{O} \text {, } \\
& U O_{2}\left(X O_{p}\right)_{m}\left(H_{2} O\right)_{5-f}^{2-2 m}
\end{aligned}
$$

where $X=\mathrm{S}, \mathrm{Se}, \mathrm{C}$ for sulfates, selenates $(p=4)$ and carbonates $(p=3)$ respectively. Sulfates and carbonates are the most common forms of uranium in the early phases of acid and basic leaching in uranium exploitation $[2,3]$. Selenates are of importance in RWR studies since the ${ }^{79} \mathrm{Se}$ isotope is thermal fission product of critical importance (in particular because of its mobility and radiological and chemical toxicity [4]). The comparison between uranium sulfates, selenates (and tellurates) is important for pure chemistry as well, as an example of homological series of ligands in coordination chemistry.

The usual experimental methodic for $\beta^{\circ}$ derivation is a speciation study [5-11]. The study consists of preparation of series of solutions all contaning fixed total concentration of uranium $c_{U}, p H$ and ionic strength $I$, but differing in the total concentration of ligand (e.g. added in the form of its respective sodium salt $-\mathrm{Na}_{2} \mathrm{SO}_{4}, \mathrm{Na}_{2} \mathrm{SeO}_{4}$, 
$\mathrm{Na}_{2} \mathrm{CO}_{3}$ ) and spectral measurement on each sample in the series (temperature $T$ is fixed, the number of solutions in the series range from 7 to several tens). Each solution will contain equilibrium mixture of $\mathrm{UO}_{2}{ }^{2+}, \mathrm{UO}_{2} \mathrm{XO}_{\mathrm{p}}$, $\mathrm{UO}_{2}\left(\mathrm{XO}_{\mathrm{p}}\right)_{2}{ }^{2-}, \mathrm{UO}_{2}\left(\mathrm{XO}_{\mathrm{p}}\right)_{3}{ }^{4-}$. The task is now to determine both individual complex spectra and the stability constants (determining the ratios of complex concentrations) at the same time from the series of above mentioned solutions spectra. The task is possible under the assumption that individual component spectra are independent of the solution composition and the solution spectra are therefore just linear combinations of the unknown individual component spectra. The mathematical solution to this problem is long time known (studied in Chemometrics) and we can address interested reader to literature [12-15]. Our approach was based on the (Parallel) Factor Analysis methods [16-18] (which exploits the Singular Value Decomposition [19]).

Because the stability constants of $1: 1,1: 2$ and 1:3 complexes are very similar and rather small, solutions where only two complex species are nonneglibly present are rather rare. Unfortunately, also the individual component spectra (both the UV-Vis absorption and TRLFS) are very similar to each other $[5,8,13]$, so the numerical analysis of the speciation study spectra is an illconditioned problem (i.e. very small variation/error in the experimental data propagate as a large error of the both individual component spectra and the stability constants).

To determine the true value of $\beta^{\circ}$ (defined by products/reactants concentration ratio extrapolated to zero ionic strength) and $\varepsilon(i, j)$ we would need the above mentioned study to be done for a serie of series (the ionic strength is varied, e.g., $0.3,1,2,3,7,10 \mathrm{~mol} \cdot \mathrm{kg}^{-1}$ ). Roughly speaking, we can derive $\beta^{\circ}$ and $\Delta \varepsilon$ values, specific for each complex from SIT-fit of the dependence of $\beta$ on $I$ (where $\beta$ is defined by the concentration ratio for non-zero ionic strength). Similarly, the serie of series (when the temperature is varied) study can uncover the values of $\Delta H^{\circ}$ and $\Delta S^{\circ}$ through Van't Hoff fit (39) [20].

Our idea was to use the theoretical, $a b$ initio, predictions of both spectroscopic (parameters of the individual component spectra) and thermodynamic properties as a hint (or constrain) in the decomposition of experimental solution spectra. Later, we have found that a similar approach was used for uranyl hydroxo- complexes by Drobot et al [106]. We also look for quantum chemistry to interpret the experimental results. The quantum chemical modelling of room temperature water solved uranyl complexes deals with - relativistic quantum effects (due to uranium atom, [21]), relatively strong electron correlation and needs for precise description of the solvation (hydration) and molecular dynamics. We were not able to produce numerical accurate (quantative) agreement between theory and experiment, but we would like to present some methodology which allows further systematic improvement to achieve that later

a A manifold of quasi-degenerated excited states with similar vibrational frequencies and equilibrium geometries is a more realistic description, however, would not change much in later derivation.

b The lowest lying triplet state according to the TDDFT/B3LYP/defTZVPP/ECP-60 method. For hydrated uranyl, however, the lowest lying (substantiated by qualitative agreement of some spectroscopic quantities achieved yet).

\section{Theoretical background}

\subsection{Uranyl compounds spectra}

The studied regions in UV-vis and in emission-wavelength domain of the TRLFS spectra were $450 \mathrm{~nm}-600 \mathrm{~nm}, 380$ $\mathrm{nm}-500 \mathrm{~nm}$ respectively (or $16.5-22$ and 20-26 thousand $\mathrm{cm}^{-1}$ ). In this regions we can think about a single electronic transition corresponding for the whole spectrum ${ }^{\mathrm{a}}$. This transition is vibrationally resolved with peaks corresponding to different vibrational quantum numbers of the initial and final states in question. The vibrational "substates" of the excited electronic state will be labeled by primed numbers (i.e. 0', 1', 2', ...), while the vibrational "substates" of the ground electronic state by non-primed numbers (i.e. $0,1,2, \ldots)$. The simplest model suppose that electronic excitations in all studied uranyl complexes are located on the central uranyl $\left(\mathrm{UO}_{2}{ }^{2+}\right)$ group and since the $\operatorname{HOMO}\left(\sigma_{\mathrm{u}}\right) \rightarrow \operatorname{LUMO}\left(\delta_{\mathrm{u}}, \phi_{\mathrm{u}}\right) \quad$ electronic excitation corresponds to the transfer of electronic density from bonding $\sigma_{\mathrm{u}}$ molecular orbital (localized on the O-U-O uranyl axis) to non-bonding orbitals localized mostly on uranium $\left(\delta_{\mathrm{u}}, \phi_{\mathrm{u}}\right)$, we can think that only symmetric vibrational mode of uranyl group force constant will be significantly affected by the electronic excitation. And, therefore, only this mode will "vibrationally resolve" the spectrum. For the simplest model, we calculated the symmetric dissociation curve for the "bare" uranyl group $\left(\mathrm{UO}_{2}{ }^{2+}\right)$ in vacuum (Fig.1), the corresponding experimental emission/luminescence spectrum of hydrated uranyl $\left(\left[\mathrm{UO}_{2}\left(\mathrm{H}_{2} \mathrm{O}\right)_{5}\right]^{2+}\right)$ is presented in Fig. 2 . The molecular orbitals discussed above have been calculated for the equilibrium geometry within the same methodics as the dissociation curves (Figs. 3,4,5,6).

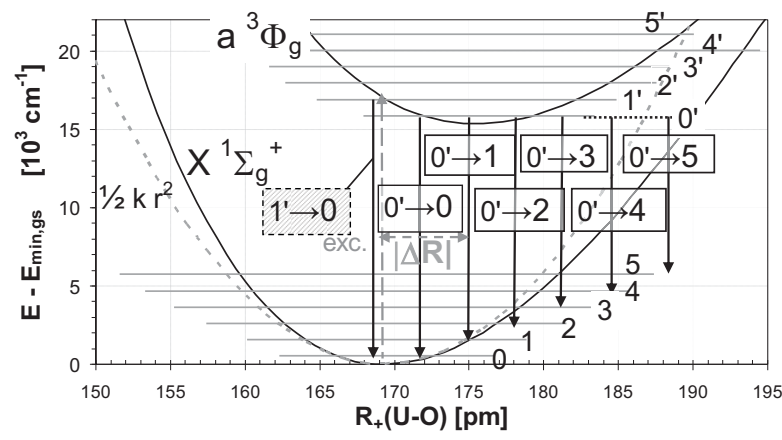

Fig. 1. The symmetric dissociation curves for "bare" uranyl ion $\mathrm{UO}_{2}{ }^{2+}$ calculated by DFT [22-24] (for the ground state, $\mathbf{X}^{1} \Sigma_{\mathrm{g}}^{+}$) and Time-dependent DFT [25-27] (for the excited state ${ }^{\mathrm{b}}, \mathbf{a}^{\mathbf{3}} \boldsymbol{\Phi}_{\mathbf{g}}$ ) with B3-LYP functional [28], def-TZVPP basis set [29] and Turbomole V6.5 [30,31] recommended Effective Core Potential [33] for uranium [32].

In Fig. 1, the vibrational states are represented by gray horizontal lines and numbered as suggested in the text above. The $R_{+}(\mathrm{U}-\mathrm{O})$ is the uranyl-oxygen bond distance ${ }^{\mathrm{c}}$,

triplet is reported to be ${ }^{3} \Delta_{\mathrm{g}}$ (which agree with our DFT/B3LYP results) [59]. The true, relativistic symmetry mix triplet state with a singlet component into $1_{\mathrm{g}}$ state.

${ }^{\mathrm{c}}$ Equal for both bonds in the uranyl ion in the symmetric mode. 
$E$ electronic energy, $E_{\text {min,gs }}$ is (here) an unimportant amount of the equilibrium ground state energy. The thick vertical arrows correspond to the transitions visible in the emission (luminescence) spectrum (Fig. 2), the gray dashed arrow corresponds to excitation transition prior to emission. The absolute value of ground and excited state equilibrium distances, $|\Delta R|=R_{\text {min,es }}-R_{\text {min, } g s}$ will be discussed later.

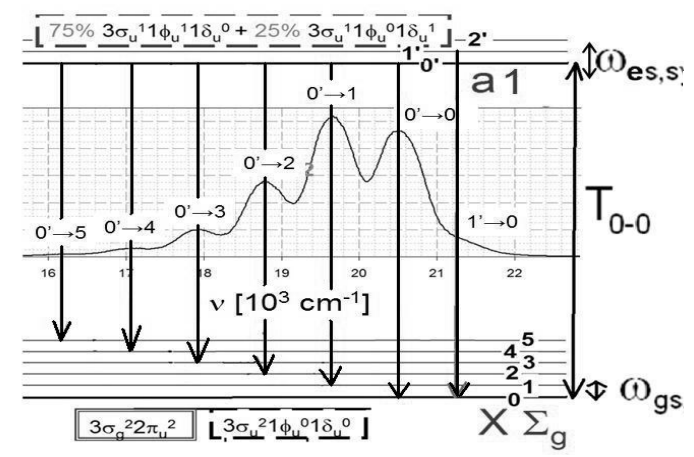

Fig. 2. The pentaaquauranyl $\left(\left[\mathrm{UO}_{2}\left(\mathrm{H}_{2} \mathrm{O}\right)_{5}\right]^{2+}\right)$ luminescence spectrum measured by TRLFS in $10^{-4} \mathrm{~mol} \cdot \mathrm{dm}^{-3} \mathrm{U}(\mathrm{VI})$ solution in $4 \mathrm{~mol} \cdot \mathrm{dm}^{-3} \mathrm{NaClO}_{4}$ and $0.01 \mathrm{~mol} \cdot \mathrm{dm}^{-3} \mathrm{HClO}_{4}$. Above and below the graph corresponding vibrational levels are shown (see Fig. 1). The vibrational levels of both ground and excited electronic state are spread equidistantly (the eventual anharmonicity of around $5-15 \mathrm{~cm}^{-1}$ [34] is within the measurement error) and the spacing corresponds to the ground state $I_{g s}$ and excited state vibrational frequencies $\left(870 \pm 15 \mathrm{~cm}^{-1}\right.$ $[35,36,41]$ and $700 \pm 15 \mathrm{~cm}^{-1}$ [37] for pentaaquauranyl complex).

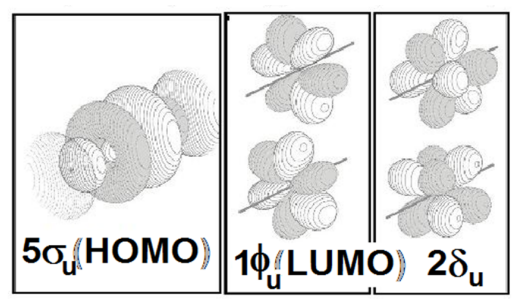

Fig. 3. The isosurfaces of constant positive (light) and negative (dark) wave-function value for the frontier orbitals of the "bare" uranyl ion within the DFT/B3LYP/def-TZVPP/ECP method. The bonding axis O-U-O is drawn as a line for $\phi_{u}$ and $\delta_{u}$ orbitals (located almost exclusively on the uranium atom alone), the cylindrical symmetric $\sigma_{u}$ orbital is winded around the axis.

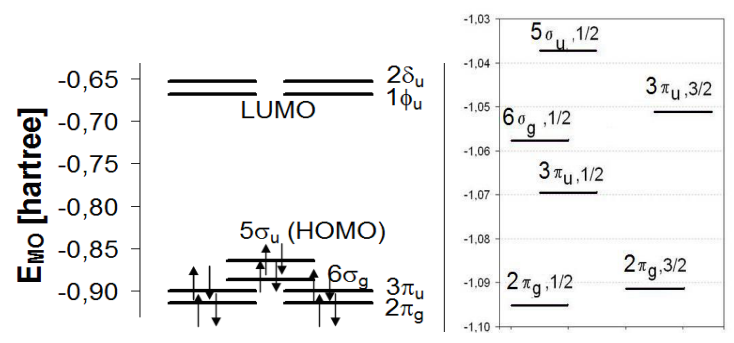

\footnotetext{
${ }^{\mathrm{d}}$ The energy axis on right does not correspond to the energy axis on left, since the former is an all-electron calculation result while the latter is ECP variant.

${ }^{\mathrm{e}}$ With respect to the Dirac-Coulomb(-Gaunt) hamiltonian, the orbital angular momentum (projected on molecular axis) is no longer good quantum number, so the " $\sigma$ ", " $\pi$ ", " $\delta$ " labels are rather for orientation. The projected total angular momentum (" $1 / 2$ ", " $3 / 2$ " written next to the orbital label) is a good quantum number. The " $1 / 2$ " are mixture of $\sigma$ - and $\pi$-orbitals, "3/2" of $\pi$ - and $\delta$-orbitals, etc.
}

Fig. 4. Diagram of frontier molecular orbitals of the "bare" uranyl ion within the DFT/B3LYP/def-TZVPP/ECP method (left). Exclusion of non-scalar relativistic effects allows double degeneracy of $\pi, \phi$ and $\delta$ orbitals as well as their orbital angular momenta well-characterisation. Diagram ${ }^{\mathrm{d}}$ of the highest lying occupied molecular orbitals (or "molecular electronic bispinors") within 4-component all electron DFT derived from DiracCoulomb-Gaunt Hamiltonian [21] (right).

Please note the (spin-orbital) splitting of the previously degenerated $3 \pi_{u}$ and $2 \pi_{g}$ energy levels $\mathrm{s}^{\mathrm{e}}$. The $\phi_{u}$ and $\delta_{u}$ lowest unoccupied orbitals exhibit similar splitting leading to numerous quasi-degenerated excited states. Under the Dirac-Coulomb(-Gaunt) description [21], the (lowest lying spectral active) excited electronic state is no longer pure triplet, but rather a linear combination of triplet and singlet ${ }^{\mathrm{f}}$ - the amount of singlet admixture allows for electromagnetic transition to the ground close-shell singlet dominated electronic state. However, we supposed that the energetic properties of the spectral active excited state are similar rather to the triplet than to the singlet state and only excited triplet states are investigated in this contribution. In the Supplementary Information, the singlet states are briefly discussed as well. It is important to stress again, that the true electronic states of molecules in question are linear combinations of components corresponding to different spin multiplicities due to their relativistic nature.

While the symmetric vibrational (stretching) mode of the uranyl group is the most active in spectral resolution, the remaining $3 N-7$ vibrational modes ${ }^{\mathrm{g}}$ will couple as well, but we can think about this coupling as about a mere change from "symmetric vibrational mode (frequency, shift)" to "effective symmetric mode (frequency, shift)" [38]. Similarly, the presence of the ligand can be, in the first approximation, seen as a perturbation changing the uranyl electronic excitation energy $T_{00}\left(0 \rightarrow 0^{\prime}\right)\left[\mathrm{cm}^{-1}\right]$, the "effective" symmetric mode vibrational frequencies in the ground state $\left(\omega_{\mathrm{gs}}\left[\mathrm{cm}^{-1}\right]\right)$ and the excited state $\left(\omega_{\mathrm{es}}\left[\mathrm{cm}^{-1}\right]\right)$ and the shift of the equilibrium U-O distance due to the excitation $(\Delta R[\mathrm{pm}])$.

The $T_{00}$ and $\omega_{g s}$ quantities can be obtained from the luminescence peak position fit (Fig. 5). Since the "hotband" in the luminescence spectra ${ }^{\mathrm{h}}$ is usually rather wide, the $\omega_{e s}$ frequency is to be accurately determined from the absorption spectra (Fig. 6) [37].

The $\Delta R$ quantity can be determined from the peak surfaces (i.e. the integrals of the spectral intensity corresponding to the individual peaks with the respect to wave-number $v$ ) dependence on vibrational quantum number (i.e. the number of the peak). This is done in Fig. 6 under the preposition that there is only one vibrational mode (the symmetric mode of the uranyl central group) active.

\footnotetext{
${ }^{\mathrm{f}}$ Electronic states are characterized by the total (spin+orbital) angular momentum projected - " $J_{z}=0$ " for the ground state and, supposedly " $J_{z}$ $=1$ " for the excited state.

${ }^{\mathrm{g}} \mathrm{N}$ is the number of atoms in the complex molecule (or supramolecular complex of the molecule and solvent molecules)

h The transition 1 ' $\rightarrow 0$ from the vibrationally excited substate of the excited electronic state, which relative intensity grows with the temperature since the initial excited state is thermally equilibrated (,thexi“) prior to emission.
} 


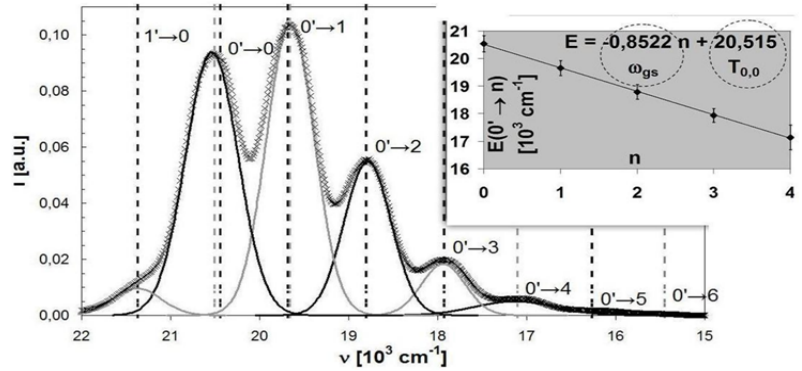

Fig. 5. (the rightmost graph with gray background) The dependence of peak maxima (in $\mathrm{cm}^{-1}$ ) on the corresponding vibrational quantum number $n$ in the ground state $\left(0^{\prime} \rightarrow n\right.$ transition). The main, white background graph shows the pentaaquauranyl luminescence spectrum with wavenumber axis in reversed order ${ }^{\mathrm{i}}$.

Fitted curve in rigthmost graph in the Fig. 5 corresponds to a single mode linear harmonic oscillators model (the ground state vibrational frequency is a slope of the fitted line and equals to $\omega_{g s}=(850 \pm 20) \mathrm{cm}^{-1}$ here $)$, the other parameter of the line fit corresponds to 0 ' $\rightarrow 0$ transition energy $T_{00}$ and was determined as $T_{00}=(20.5 \pm$ $0.1) \cdot 10^{3} \mathrm{~cm}^{-1}$ here.

The spectra (either absorption or emission /luminescence) in the spectral region of interest can be written as a sum of the individual peaks $V_{\Delta n}$,

$$
I(v)=\sum_{\Delta n=+}^{5} V_{\Delta n}(v),
$$

where $v$ is the wavenumber in $\mathrm{cm}^{-1}$, the lower index $\Delta n$ corresponds to the difference of vibrational quantum numbers, $\Delta n=n-n$ '. Each peak can be modelled as Voigt profile ([39,40], gaussian broadened Lorentzian profile)

$$
\begin{aligned}
& V_{\Delta n}(v)=V\left(v_{\Delta n}, \sigma_{\Delta n}, \gamma_{\Delta n}, S(\Delta n) ; v\right) \\
& =S(\Delta n) \cdot \frac{\gamma_{\Delta n}}{\sqrt{2} \sigma_{\Delta n} \pi^{3 / 2}} \int_{-\infty}^{+\infty} \frac{\exp \left(-\left(v^{\prime}-v_{\Delta n}\right)^{2} / 2 \sigma_{\Delta n}^{2}\right)}{\left(\left(v-v_{\Delta n}-v^{\prime}\right)^{2}+\gamma_{\Delta n}^{2}\right)} d v^{\prime}
\end{aligned}
$$

where $v_{\Delta n}$ is the peak maximum (plotted in the graybackground graph in Fig. 4 against the $\Delta n \geq 0$, the fit corresponds to $\left.E\left(0^{\prime} \rightarrow n\right)=c v_{\Delta n}=c \omega_{g s} \Delta n+T_{00}\right), \sigma_{\Delta n}$ and $\gamma_{\Delta n}$ are width-parameters of Gaussian and Lorentzian part of the peaks respectively and $S(\Delta n)$ determine the peak contribution to spectrum (and is related to the integrated peak intensity via (6)). The Voigt profile can be easily evaluated via the real part of Faddeeva function $[42,43] w$,

$$
V_{\Delta n}(v)=\frac{\operatorname{Re}\left[w\left(\frac{v-v_{\Delta n}+i \gamma_{\Delta n}}{\sigma_{\Delta n} \sqrt{2}}\right)\right]}{\sigma_{\Delta n} \sqrt{2}}
$$

\footnotetext{
${ }^{\mathrm{i}}$ To resemble the characteristic shape of uranyl luminesce spectra when plotted against wavelength) and highlight Voigt profile fit of the individual peaks $V_{\Delta n}(v)(2)$.
}

which is for complex variable $z$ defined via complementary error function erfc. The " $i$ " in formulae (4) and (5) stands for imaginary unit $\left(i^{2}=-1\right)$,

$$
\begin{aligned}
& w(z) \equiv \exp \left(-z^{2}\right) \operatorname{erfc}(-i z) \\
& =e^{-z^{2}}\left(1+\frac{2 i}{\sqrt{\pi}} \int_{0}^{z} e^{t^{2}} d t\right) \\
& S(\Delta n)=\int_{-\infty}^{+\infty} V_{\Delta n}(v) d v
\end{aligned}
$$

In our simplified model, we adapt Born-Oppenheimer approximation [44] and neglect both nuclear coordinates contribution to transition moment operator and possible dependence of its matrix element between electronic states on nuclear coordinates. As a result, the integrated peak intensities ratio (here with $n^{\prime}=0$ fixed) equals to ratio of squares of the absolute values of Franck-Condon factors [45-48,50]

$$
\frac{S(\Delta n)}{S(0)}=\frac{\left|F\left(n^{\prime}, n\right)\right|^{2}}{\left|F\left(0^{\prime}, 0\right)\right|^{2}}
$$

defined as scalar products of the corresponding $n$ '-th vibrational wave function in the excited state and $n$-th vibrational wave function in the ground electronic state,

$$
\begin{aligned}
& F\left(n^{\prime}, n\right)=\left\langle\psi_{n^{\prime}}^{(e s)} \mid \psi_{n}^{(g s)}\right\rangle \\
& \left\langle\psi_{n^{\prime}}^{(e s)} \mid \psi_{n}^{(g s)}\right\rangle=\int_{-\infty}^{+\infty} \bar{\psi}_{n^{\prime}}^{(e s)}(R) \psi_{n}^{(g s)}(R) d R .
\end{aligned}
$$

In the formulae above, $n$ ' and $n$ might, in general, stand for arrays of non-negative integers and the integration in (9) might be with respect to all $3 N-6$ internal degrees of freedom in the molecule, but within one-mode approximation we work with $n$ ', $n$ single non-negative integers and left side of (9) one-dimensional integral. In the harmonic approximation [49] which can be adapted since the uranyl group show, in our experiments, unmeasurable anharmonicity, the corresponding vibrational wave function has a form [48],

$$
\psi_{n}^{(y)}(R)=\frac{\pi^{-1 / 4}}{\sqrt{2^{n} n !}} H_{n}\left(\xi_{y}\right) \exp \left(-\left(\xi_{y}-\xi_{y, \text { min }}\right)^{2} / 2\right)
$$

where $y \in\{\mathrm{es}, \mathrm{gs}\}$ denotes the electronic state, $H_{n}$ is the $n$ th Hermitian polynomial [51,52], $\zeta_{y}$ and $\zeta_{y, m i n}$ are dimensionless normal mode coordinate and equilibrium value (i.e. $\zeta_{y}$ and $\zeta_{y, \min }$ represent scaled $\mathrm{U}-\mathrm{O}$ bond distance $R$ and its equilibrium value)

$$
\xi_{y} \equiv R / R_{0, y},
$$

The scaling constants/units are state-specific due to frequency $\omega_{y}$ dependence 


$$
R_{0, y}=\sqrt{/ \mu \omega_{y}},
$$

where $\mu$ is the reduced mass of the respective normal mode (i.e. symmetric vibrational mode of the uranyl group, in case oxygen nuclear masses equals $\mathrm{s}^{\mathrm{j}}$, it is multiple of the oxygen nuclear mass, see (40)).

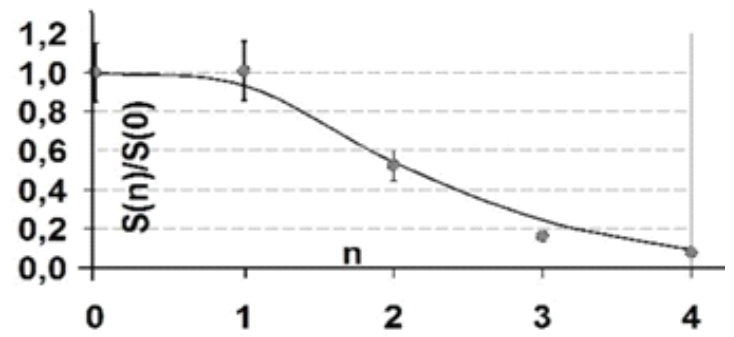

Fig. 6. The ratio of integrated peak intensities $\mathrm{S}(n) / \mathrm{S}(0)$, defined by (3) corresponding to the 0 ' $\rightarrow n$ transitions in the experimental pentaaquauranyl luminesnce spectrum (Fig. 2) - gray filled round circles.

The smooth curve in Fig. 6 above corresponds to the fit to theoretical dependence for a single mode model of two (by $\Delta R$ ) origin-shifted harmonic oscillators with different frequencies $\left(\omega_{g s} \text { and } \omega_{e s}\right)^{\mathrm{k}}$. The fitted [53] value was $\Delta R=(16 \pm 4) \mathrm{pm}$, which doesn't agree well with the same quantity fitted from the absorption spectrum $\Delta R=$ $(28 \pm 8) \mathrm{pm}^{1}$

Of course, this is for mere classification of the spectral parameters and first-sight interpretation of the spectra, in particular quantum chemical computations, whole (supramolecule) has to be treated as an indivisible system.

\subsection{Model of absorption and luminescence signal of a multicomponent aqueous solution}

For the absorption solution spectra, we used the multicomponent (additive) variant of the Lambert-Beer law [55] in the form

$$
Y_{i}(\lambda)=\sum_{m=1}^{b} C_{i m} Z_{m}(\lambda)+n_{i}(\lambda)
$$

where $Y_{i}(\lambda)$ is the $i$-th spectrum $^{\mathrm{m}}$ evaluated at the wavelength $\lambda, C_{i m}$ the molar concentration and $Z_{m}$ spectrum of the individual chemical species (e.g. $\mathrm{UO}_{2}{ }^{2+}$, $\mathrm{UO}_{2} \mathrm{SO}_{4}, \mathrm{UO}_{2}\left(\mathrm{SO}_{4}\right)_{2}{ }^{2-}, \ldots$ for the sulphate-system). The total number of distinguishable components is denoted as $b$. The $n_{i}(\lambda)$ is the noise function.

The optical length $l$ is incorporated in the $Z_{m}(\lambda)$ here as an overall multiplicative constant, so precisely,

\footnotetext{
${ }^{\mathrm{j}}$ Otherwise, there is no uranyl symmetric stretching mode, just a mode most close to it and its inverse reduced mass will be proportional to sum of inverse masses of both oxygen nuclei.

${ }^{\mathrm{k}}$ The theoretical dependence is given by ratio of Franck-Condon factors for the above mentioned simplified model [56] and can be found together with the multi-mode generalization e.g. in $[57,58]$.

${ }^{1}$ Putting the single mode approximation in the serious doubts - mostly for the absorption spectrum, where experimental data and fitted curve disagree to a greater extend.

${ }^{\mathrm{m}}$ For an UV-Vis absorption speciation study we can think about $i$-th solution spectrum. That is the spectrum for a solution in series
}

$$
Z_{m}(\lambda)=l \cdot \varepsilon_{m}(\lambda)
$$

where $\varepsilon_{m}(\lambda)$ is the molar absorption coefficient for the $m$ th species and wavelength $\lambda$.

For the TRLFS spectra the same additive law as (13) was adapted, except the $Z_{m}(\lambda)$ has to be replaced by multidomain function (depending on emission wavelength $\lambda$, delay between the excitation pulse and beginning of the luminescence signal integration $t$, excitation wavelength $\lambda_{\text {exc }}$ and possible other parameters described below). For this case we can write

$$
Z_{m}=Z_{m}\left(\lambda, t, \lambda_{e x c}, E_{e x c}\right),
$$

where $E_{\text {exc }}$ is an excitation pulse energy. We can model the individual component spectra

$$
Z_{m}=S_{m}\left(\lambda_{e x c}, E_{e x c}\right) \cdot T_{m}(t) \cdot \overline{Z_{m}}\left(\lambda_{e x c}, \lambda\right),
$$

as a products of the energy-dependent saturation part $S$, temporal part $T$ and pure-spectral part $\overline{Z_{m}}$. The respective terms can be further modelled $[13,61]$ as

$$
\begin{aligned}
& S_{m}\left(\lambda_{e x c}, E\right)=\mu_{m} E_{s a t, m}\left(1-\exp \left(-\frac{E}{E_{s a t, m}\left(\lambda_{\text {exc }}\right)}\right)\right) \\
& T_{m}(t)=\tau_{m, i}\left(1-\exp \left(-\Delta t / \tau_{m, i}\right)\right) \cdot \exp \left(-t / \tau_{m, i}\right)
\end{aligned}
$$

and approximatively

$$
\overline{Z_{m}}\left(\lambda_{\text {exc }}, \lambda\right)=\varepsilon_{m}\left(\lambda_{e x c}\right) \cdot \overline{\overline{Z_{m}}}(\lambda) .
$$

Where $E$ (17) is excitation laser pulse energy, $E_{\text {sat, } m}$ is saturation energy (a parameter, only very slightly dependent on both $m$ and $\lambda_{e x c}$ ). The formula (17) says that increase in excitation laser energy will not yield always the same amount of signal per added mJ. Eventually (almost) all molecules will be excited and the signal cannot reach higher. For very low energies (in praxis for $E<0.7 \mathrm{~mJ}$, the $O(E)$ part of (20) can be neglected with the respect to measurement errors) the energy dependence of $S_{m}$ and therefore of the whole luminescence signal is linear as can be seen by Taylor expansion of (17),

$$
S_{m}(E)=\mu_{m} E-\frac{\mu_{m}}{2 E_{s a t, m}}+E^{2} .
$$

$O(E)$

However, the good signal:noise ratio is achieved for rather higher excitation pulse energies ${ }^{\circ}(E \approx 1.5 \mathrm{~mJ}$, or up to $E \approx$

characterised by total ligand concentration $c_{L, i}$ (unique for the $i$-th solution) and total uranium concentration $c_{U}$, ionic strength $I, p H$ and temperature (those quantities are kept the same for all solutions in the series).

${ }^{n}$ The monoexponential decay is rather approximation and [61] suggest that mostly probably too rough.

"In theory, the "saturation area", where signal is almost independent on energy since energy is large enough to excite almost all molecules would be the perfect choice - but it would heat excessively both sample (changing measured properties) and the laser apparatus. On contrary the 
$4 \mathrm{~mJ}$ ) and the non-linearity of the dependence of luminescence signal on $E$ has to be taken into account ${ }^{\mathrm{p}}$.

The temporal dependence $T$ is parametrized by luminescence lift-time $\tau_{m, i}$ of the $m$-th species in the $i$-th solution and consist of the time-independent pre-factor resulting from the integration of the signal in CCD camera (integration time $\Delta t$ ) and the supposed mono-exponential decay of the excited state (yet there are suggestions that in some cases, slightly more complicated, e.g. bi-exponential model should be adopted instead). The luminescence lifetime is, in general, dependent not only on the luminescence active species (indexed $m$ ) but also on the overall composition of the solution, most importantly on the concentration of the quenchers and on the temperature. The simplest, yet relatively accurate model for this dependence is of Stern-Volmer type ${ }^{q}[1,60]$,

$$
\frac{1}{\tau_{m, i}}=\frac{1}{\tau_{m, i}^{(0)}}+\sum_{q \in Q} k_{q}[q]
$$

where $\tau_{m, i}^{(0)}$ is radiation life-time of the luminescence active excited electronic state (i.e. luminescnce life-time in absence of any quenching species), $[q]$ stands for the molar concentration of quenching specie " $q$ ", $k_{q}$ is the respective rate constant for which we can suppose [36] ${ }^{\mathrm{r}}$ the Arhenius law dependence on thermodynamic temperature $T$,

$$
k_{q}=A_{q} \exp \left(-\frac{E_{A, q}}{R T}\right)
$$

where $A_{q}$ is the frequency factor, $E_{A, q}$ activation energy and $R$ universal gas constant. The term "quenching" is used here loosely - the point is, that some species $\left(\mathrm{H}_{2} \mathrm{O}^{\mathrm{s}}, \mathrm{HSO}_{4}{ }^{-}\right.$ , $\mathrm{HSeO}_{3}^{-}$[9], organic traces [62]) were proven to decrease the $\tau_{m, i}$ value and the respective dependence form can be supposed to be (21) and (22). But the actual mechanism of the non-radiative energy transfer remains unclear ${ }^{t}$ [61].

For a constant physical-chemical conditions ( $\mathrm{pH}$, ionic strength, temperature, electrolyte type), the $\tau_{m, i}$ increase with decreasing number of water molecules in the first coordination sphere, i.e.

$$
\begin{aligned}
& \tau_{i}\left(U O_{2}^{2+}\right)<\tau_{i}\left(U O_{2} X O_{4}\right)<\tau_{i}\left(U O_{2}\left(X O_{4}\right)_{2}^{2-}\right)< \\
& \quad<\tau_{i}\left(U O_{2}\left(X O_{4}\right)_{3}^{4-}\right)
\end{aligned}
$$

where $X=\mathrm{S}$, Se and where the simplified formula for the species in question was putted in round parenthesis instead of being denoted by index $m$. We suppose that the

\footnotetext{
"linear response area" $(E<<0.7 \mathrm{~mJ})$ would be best for deconvolution of the energy dependence, but the signal: noise ratio would be low.

${ }^{\mathrm{p}}$ It is ideal to keep the settings of the laser system such that $E$ vary as less as possible, but rarely it is possible to keep relative square root variations under 5\%. And therefore we cannot simply incorporate energy dependence into some pre-multiplicative constant.

${ }^{\mathrm{q}}$ Could apply for both intermolecular quenching (collisional, diffuse) and intramolecular quenching (Förster, Dexter), difference will be in the $k_{q}$ interpretation (see Supplementary Info).

${ }^{\mathrm{r}}$ Please see Fig. 21 and 22 on $13^{\text {th }}$ page of [36].

${ }^{\mathrm{s}}$ For example, in the system $\mathrm{UO}_{2}{ }^{2+}-\mathrm{NaClO}_{4}-\mathrm{HClO}_{4}-\mathrm{H}_{2} \mathrm{O}$, for constant $p H$, the higher is ionic strength, the longer is observed $\left[\mathrm{UO}_{2}\left(\mathrm{H}_{2} \mathrm{O}\right)_{5}\right]^{2+}$
}

inequality (23) is due to the similar dependence of $\tau_{m, i}^{(0)}$ on the "intramolecular (coordinated) water concentration", i.e. the $\tau_{m, i}^{(0)}$ and as a result the $\tau_{m, i}$ increase in (23) as the number of water molecules coordinated in the equatorial plane to uranium in molecule decrease with the number of other ligand $\left(\mathrm{XO}_{4}{ }^{2-}\right)$ increasing.

The formula (19) says that approximately, the twowavelength domain luminescence spectrum is a product of an absorption $\left(\varepsilon_{m}\left(\lambda_{\text {exc }}\right)\right)$ and emission spectra $\left(\overline{\overline{Z_{m}}}(\lambda)\right)$. Since most laser systems in TRLFS measurement are tunable, it is possible to measure both dependence and, in most general case - gain the information from the all three domains (modes, $\left.\lambda_{\text {exc }}, \lambda, t\right)$ at the same time [67]. However, the tunning (change in $\lambda_{\text {exc }}$ ) is much slower than recording the temporal dependence (change in $t$ ) or measurement in the $\lambda$-domain (realised by a dispersion element before the CCD camera chip) and therefore, in most of our measurements, $\lambda_{\text {exc }}$ was being kept constant and $\overline{\overline{Z_{m}}}$ is identified with $\overline{Z_{m}}$ absorbing the $\lambda_{\text {exc }}$ dependent factor $\varepsilon_{m}\left(\lambda_{\text {exc }}\right)$ into the multiplicative constant $\mu_{m}$ specific for the particular luminescence active species, but, almost independent on any other parameter or variable.

To distinguish the premultiplicative factor $\mu_{m}$ (17) from other terms, normalization condition on the spectrum in question should be applied. The possible variants include $L^{2}$ continuous norm (24), $l^{2}$ discrete norm (25) and a maximum norm $l^{\infty}(26)$,

$$
\begin{aligned}
L^{2}\left[Z_{m}\right] & \equiv \frac{1}{\lambda_{\max }-\lambda_{\min }} \sqrt{\int_{\lambda_{\min }}^{\lambda_{\max }} Z_{m}^{2}(\lambda) d \lambda}=1, \\
l^{2}\left[Z_{m}\right] & \equiv \frac{1}{N} \sqrt{\sum_{l=1}^{N} Z_{m}^{2}\left(\lambda_{l}\right)}=1 \\
l^{\infty}\left[Z_{m}\right] & \equiv \max _{\lambda \in\left\langle\lambda_{\min }, \lambda_{\max }\right\rangle} Z_{m}(\lambda)=1 .
\end{aligned}
$$

where $\lambda_{\max }$ and $\lambda_{\min }$ are boundaries of the spectral region of the interest, $N$ is the number of spectral points, $\lambda_{I}=\lambda_{\text {min }}$, $\lambda_{N}=\lambda_{\max }$.

\section{$2.3 \mathrm{UO}_{2}{ }^{2+}-\mathrm{XO}_{\mathrm{p}}{ }^{2-}-\mathrm{H}_{2} \mathrm{O}$ speciation and Thermodynamic properties of uranyl complexes}

The uranyl complex molecules in question consist of (none, one, two or three) $\mathrm{XO}_{\mathrm{p}}{ }^{2-}$ ligands coordinated to the uranium atom in the linear $\mathrm{O} \equiv \mathrm{U} \equiv \mathrm{O}$ group $^{\mathrm{v}}$ in the equatorial plane (plane perpendicular to the uranyl group,

luminescence life-time. The luminescence life-time ionic strength dependence could be explained by equation (21) with single quenching species, $q=\mathrm{H}_{2} \mathrm{O}$, since higher ionic strength imply lower molar concentration of water in the water solution. First author's preliminary measurements [36] (Fig. 20) are in agreement with that fit.

${ }^{\mathrm{t}}$ To cite [61] exactly "The nature of aqueous uranyl deactivation is still under discussion, and both photochemical and physical mechanisms of excided state quenching are proposed."

"Well documented in first table in [63]

${ }^{v}$ For uranium-oxygen triple bond character - [66]. 
[2]). In case of no ligands, the hydration number of uranyl group was determined as $5[2,64,65]$, i.e. pentaaqua uranyl complex $\left[\mathrm{UO}_{2}\left(\mathrm{H}_{2} \mathrm{O}\right)_{5}\right]^{2+}$, but with ligands, the coordination number of the uranyl group can be either 5 or 6 [2]), also sulfate, selenate and carbonate ligands can coordinate by either one oxygen donor atom $\left(\kappa^{1}-\right.$, monodentate coordination) or by two oxygen donor atoms $\left(\kappa^{2}-\right.$, bidentate coordination). As schematically shown in Fig. 7.

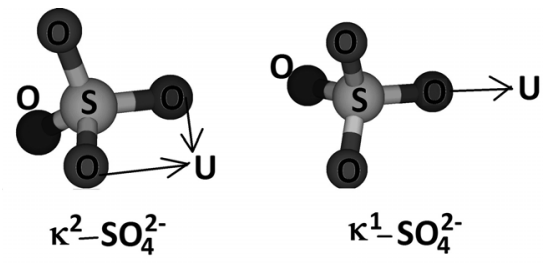

Fig. 7. Schematic view of bidentate $\left(\kappa^{2}-\right)$ and monodentate $\left(\kappa^{1}-\right)$ coordination of sulfate ligand to uranium atom. The ligand has two $\left(\kappa^{2}-\right)$ or one $\left(\kappa^{1}-\right)$ donor oxygen atom available.

For 1:1 sulfate complex this leads to four possibilities (the simplified description in the round parenthesis describe ligand bonding and uranyl coordination number) - $\left[\mathrm{UO}_{2}\left(\kappa^{2}-\mathrm{SO}_{4}\right)\left(\mathrm{H}_{2} \mathrm{O}\right)_{3}\right] \quad\left(\kappa^{2} \mathrm{co} 5\right), \quad\left[\mathrm{UO}_{2}\left(\kappa^{2}-\mathrm{SO}_{4}\right)\left(\mathrm{H}_{2} \mathrm{O}\right)_{4}\right]$ $\left(\kappa^{2} \operatorname{co} 6\right), \quad\left[\mathrm{UO}_{2}\left(\kappa^{1}-\mathrm{SO}_{4}\right)\left(\mathrm{H}_{2} \mathrm{O}\right)_{4}\right]\left(\kappa^{2} \cos \right)$ and $\left[\mathrm{UO}_{2}\left(\kappa^{1}-\right.\right.$ $\left.\left.\mathrm{SO}_{4}\right)\left(\mathrm{H}_{2} \mathrm{O}\right)_{5}\right]\left(\kappa^{2} \mathrm{co} 6\right)$, while for 1:2 sulfate complex there are six possible molecular geometries in total $\left(\kappa^{22}, \kappa^{12}\right.$ and $\kappa^{11}$ ligand bonding with either $\cos$ or co6 total coordination number) and for 1:3 sulfate complex eight (!). In reality we can suppose that there will be only the most symmetric variant for the uranyl tris(sulfate) $-\left[\mathrm{UO}_{2}\left(\kappa^{2}-\right.\right.$ $\left.\left.\mathrm{SO}_{4}\right)_{3}\right]^{4-} \quad\left(\kappa^{222} \mathrm{co} 6\right)$ and that among the six isomers/conformers of uranyl bis(sulfate) and four of uranyl monosulfate only some will be energetically favoured and therefore measurably present in the solution. In particular, the combination of $\kappa^{1}$-bonding and higher coordination number co6 would be disfavoured. But both experimental data [68] and theoretical quantum chemical calculations $[68,69]$ suggests that more than one, possibly more than two isomers are present together for both monoand bis- sulfates and the same possibly applies for selenates.

In the rest of this section the coordinated water molecules will be omitted for simplicity, yet the change of the water molecules number in the reaction stechiometry still kept in mind. Similarly, the $\kappa^{1}-/ \kappa^{2}$-coordination mode isomery is omitted. In fact, to all isomers discussed above might be assigned individual stability constants (29)-(32), SIT-interaction parameters $\varepsilon(i, j)(33)$ (where $i$ stands for the luminescence active species and $j$ for main electrolyte ionic species $-\mathrm{Na}^{+}, \mathrm{ClO}_{4}^{-}, \mathrm{SO}_{4}{ }^{2-}, \mathrm{HSO}_{4}^{-}, \mathrm{H}_{3} \mathrm{O}^{+}$) and spectra. By precise chemometric analysis of multiple solution series (differing by ionic strength and $p H$, possible also $c_{U}$ ), possibly for several temperatures it might be possible to distinguish two or more isomers of complex with the given stechiometry. For example to distinguish $\left[\mathrm{UO}_{2}\left(\kappa^{2}-\mathrm{SO}_{4}\right)\left(\mathrm{H}_{2} \mathrm{O}\right)_{3}\right]\left(f_{m}=2\right.$, see (27), (31) and (33) below) from $\left[\mathrm{UO}_{2}\left(\kappa^{1}-\mathrm{SO}_{4}\right)\left(\mathrm{H}_{2} \mathrm{O}\right)_{4}\right]\left(f_{m}=1\right)$. Yet only EXAFS study was able to do this reliably [68]. The

${ }^{\mathrm{w}}$ In the simplest case function of chosen electrolyte, $I$ and temperature $T$.
UV-vis or TRLFS study would need an uninterrupted several weeks lasting continual access to a very stable measurement system - which we didn't achieve yet.

The aqueous uranyl - sulfate $\left(\mathrm{UO}_{2}{ }^{2+}-\mathrm{SO}_{4}{ }^{2-}-\mathrm{H}_{2} \mathrm{O}\right)$ system is characterised by chemical equilibria

$$
\begin{array}{lc}
\mathrm{UO}_{2}^{2+}+\mathrm{mSO}_{4}^{2-} & \mathrm{UO}_{2}\left(\mathrm{SO}_{4}\right)_{m}^{2-2 m}+f_{m} \mathrm{H}_{2} \mathrm{O},(27) \\
\mathrm{HSO}_{4}^{-}+\mathrm{H}_{2} \mathrm{O} & \mathrm{SO}_{4}^{2-}+\mathrm{H}_{3} \mathrm{O},(28)
\end{array}
$$

characterized by concentration-defined ("concentrational") equilibrium "constants",

$$
\begin{aligned}
& \beta_{m}=\frac{\left[\mathrm{UO}_{2}\left(\mathrm{SO}_{4}\right)_{m}^{2-2 m}\right]}{\left[\mathrm{UO}_{2}^{2+}\right]\left[\mathrm{SO}_{4}^{2-}\right]^{m}} \\
& K_{2}=\frac{\left[\mathrm{SO}_{4}^{2-}\right]}{\left[\mathrm{HSO}_{4}^{-}\right]} \cdot 10^{-p H},
\end{aligned}
$$

where $[X]$ stands for the molal $\left(\mathrm{mol}^{-} \mathrm{kg}_{\mathrm{w}}{ }^{-1}\right.$, i.e. moles in 1 $\mathrm{kg}$ of the water) concentration of the specie $X, m \in\{1,2$, $3\}$ and $f_{m}$ is a parameter discussed in later text. The true, thermodynamic constants $\beta_{m}^{o}, K_{2}^{o}$ are defined through chemical activities of all species present in the chemical reaction. Denoting $a(X)$ the chemical activity of specie $X$,

$$
\begin{aligned}
\beta_{m}^{o} & \equiv \frac{a\left(\mathrm{UO}_{2}\left(\mathrm{SO}_{4}\right)_{m}^{2-2 m}\right) a\left(\mathrm{H}_{2} \mathrm{O}\right)^{f_{m}}}{a\left(\mathrm{UO}_{2}^{2+}\right) a\left(S O_{4}^{2-}\right)^{m}}, \\
K_{2}^{o} & =\frac{a\left(S O_{4}^{2-}\right)}{a\left(H S O_{4}^{-}\right)} \cdot 10^{-p H} .
\end{aligned}
$$

The relation between the two kind of constants, i.e. the dependence of the concentrational "constants" (29)-(30) on the truly constant thermodynamic parameters (31)-(32) and concentration of all species present in the solution can be modelled by Specific Ion Interaction Theory (SIT) [7072] via equations ("SIT equations"),

$$
\begin{aligned}
& \log \beta_{m}=\log \beta_{m}^{o}+z_{m}^{2} D(I) \Delta \sum_{k}(\varepsilon-)_{m k}[k] \Delta f_{m} \log +a_{w} \\
& \log K_{2}=\log K_{2}^{o}+3 D(I)-\sum_{k}(\Delta \varepsilon)_{0, k}[k]+f_{0} \log a_{w},(33)
\end{aligned}
$$

where aw is water activity ${ }^{\mathrm{w}}[k]$ is the molality of specie " $k$ ", $\Delta \varepsilon_{m k}$ is a linear combination of SIT interaction parameters $\varepsilon(i, j), \Delta z_{m}^{2}=-2,-2,0$ for $m=1,2,3, D(I)$ is a Debye-Hückel term ([73,74], a function of ionic strength ${ }^{\mathrm{x}}$ of a form (34))

$$
D(I)=\frac{A \sqrt{I}}{1+B \sqrt{I}},
$$

where constants $A=0.509 \mathrm{~kg} \mathrm{~kg}^{1 / 2} \cdot \mathrm{mol}^{-1 / 2}$ and $B=1.5$ $\mathrm{kg}^{1 / 2} \cdot \mathrm{mol}^{-1 / 2}$ for $25^{\circ} \mathrm{C}$ for their (slight) temperature dependence see [74]. The SIT equations are in some cases

\footnotetext{
${ }^{x}$ Ionic stength $I$ is defined as $I=\frac{1}{2} \sum_{k}[k] q_{k}^{2}$, where $[k]$ is a molal concentration and $q_{k}$ charge-number of $k$-th specie in the solution.
} 
simplified into an approximative form [74], where $\beta_{m}$ depends on concentrations only through ionic strength, i.e.

$$
\log \beta_{m}=\log \beta_{m}^{o}+z_{m}^{2} D(I) \Delta \varepsilon_{m} I-f_{m} \Delta \log a_{w} .
$$

Together with the bilantion equations,

$$
\begin{aligned}
c_{U} & =\sum_{m=0}^{3}\left[\mathrm{UO}_{2}\left(\mathrm{SO}_{4}\right)_{m}^{2-2 m}\right] \\
c_{S} & =\left[\mathrm{SO}_{4}^{2-}\right]+\left[\mathrm{HSO}_{4}^{-}\right]+\sum_{m=1}^{3} m\left[U \mathrm{U}_{2}\left(\mathrm{SO}_{4}\right)_{m}^{2-2 m}\right]
\end{aligned}
$$

where left sides are total uranium and sulphate molalities, the SIT equations (33) fully determine the speciation model, i.e. the dependence of the model concentration of $m$-th spectral active specie on the concentration parameters of the $i$-th solution,

$$
C_{i m}=C_{i m}\left(\beta, c, c_{S, i}\right)
$$

Where $c_{S, i}$ is the total sulfate molal concentration in the $i$-th solution, $c$ stands for all other $(i$-th) solution parameters and $\beta$ stands for the stability constants (31),

(32) and $(\Delta \varepsilon)_{m k}$ SIT parameters (33), or for stability constants (29)-(30) in the case of the simplified model (35). The parameters $\beta$ are then determined through least-square (in general maximum likelihood) based chemometrical method from the experimental spectral data together with the spectral parameters discussed in previous section 2.2.

The speciation is temperature dependent mostly through temperature dependence of the stability constants. We limited ourselves to the case of temperature independent reaction enthalpies $\Delta H_{m}^{o}$ and entropies $\Delta S_{m}^{o}$ (for the studied temperature interval $10^{\circ} \mathrm{C}-45^{\circ} \mathrm{C}$ ) a therefore Van't Hoff isotherm [20] can be used for the description,

$$
\ln \beta_{m}^{o}=-\frac{\Delta H_{m}^{o}}{R T} \quad \frac{\Delta S_{m}^{o}}{R} .
$$

\subsection{Quantum chemical description of uranyl complexes in aqueous solutions}

We ought to study eigenvalues and eigenstates of molecular hamiltonians corresponding to the hydrated species in question - this is done directly through the true $a b$ initio (wave-function based) methods such as HartreeFocks method (HF, SCF), post-Hartree Fock methods (Moller-Pleset perturbational MP2 method, limited approximate configuration interaction CIS(D) [81] and $\mathrm{CC} 2$ as the simplest method from the coupled-clusters family) [24]. In contrast to the wave-function based methods, there is also, possibility to access the energy level values through equations for electronic density - by Density Functional Methods (DFT) [22-24]. Though the DFT could theoretically yield results fully including

${ }^{\mathrm{y}}$ Becke-Pedrew (B-P) functional consists of Exchange part :S[82,83]+B88[86], Correlation part:VWN(V)[84]+P86[87]. electron correlation with a very low computational costs (similar to HF), the problem is that the yet known density functional are only approximate. In particular, the in chemistry most widely used, hybrid functional B3-LYP (Becke, three-parameter, Lee-Yang-Parr, [28,82-85]) had his three empirical parameters fitted to formation enthalpies of molecules with light atoms and its usability for uranium containing systems is yet in question (however, referring to previous positive tests of B3-LYP for uranyl systems, [75-80,34], we can suppose the methodics is at least accurate for qualitative analysis).

To be able to exploit the resolution-of-identity technique (significantly accelerating computations) in Turbomole V6.5 [30,31], we used the GGA (Generalized Gradient Approximation), non-hybdrid, $\mathrm{P}-\mathrm{B}^{\mathrm{y}}$ functional as well.

The calculations mentioned above were done by Turbomole V6.5 program [30,31] with only part of scalar relativistic effects included via the Effective Core Potential (ECP, [32,33]). In this approach, the inner 60 electrons $^{z}$ on the uranium atom are included by an effective potential in which the other electrons motions are described by non-relativistic Schrodinger equation (or in particular Restricted Hartree-Fock equations + post-HF treatment as written above or the Restricted Kohn-Sham equations of DFT). The effective core potentials also allow for approximative inclusion of finite-size nuclear effects and simplify electronic calculations in general (reducing the number of electrons treated explicitly).

Only few calculations were done via all-electron fourcomponent DFT/B3LYP based on Dirac-Coulomb-Gaunt (DCG) hamiltonian [21] via the DIRAC 13 software [88] (e.g. the molecular orbital diagram detail showing splitting in the right part of Fig. 4). The splitting of molecular orbitals is a vector relativistic effect and cannot by included by scalar ECP method described in previous paragraph. The Dirac-Coulomb (DC) or DCG hamiltonians are essential to description of the true symmetry properties of ground and excited state wavefunctions (which are, e.g. for free $\mathrm{UO}_{2}{ }^{2+}$ now eigenfunctions of $J_{z}-$ the total (spin+orbital) angular momentum projected on molecular axis and not eigenfunction of either the orbital $L_{z}$ or spin $s_{z}$ part alone) and calculation of electronic transition moments and therefore estimation of the $\mu_{m}$ quantity from (17) as well as the norm of the absorption spectra (while for its shape, FranckCondon factors based on scalar ECP results are sufficient).

For the hydration modelling we tried to use the simple variant of polarized continuum model (COSMO) incorporated in Turbomole V6.5 [89], but abandoned this approach after failing to achieve meaningful values of thermodynamic properties - $\beta_{m}^{o}=-\mathrm{RT} \ln \Delta G_{m}^{o}, \Delta H_{m}^{o}$ and $\Delta S_{m}^{o}$. Therefore, more precise method of explicit hydration was adapted. From first estimates on uranyl symmetric stretching mode vibrational frequency in both ground and excited electronic state and $T_{00}$ excitation energy which compares well with experiment, we believe

\footnotetext{
${ }^{\mathrm{z}}$ most influenced by the relativistic effects due to the higly charged uranium nuclei
} 
that one complete sphere of water molecules ${ }^{\text {aa }}$ fully surrounding the complex in question (forming together supramolecular complex) might be enough at least for spectroscopic properties estimation. Requirement on minimizing the computational artefacts connected to the surface tension on the artificial supramolecular complex boundaries lead to need to use spherical supramolecules with up to 65 solvating water molecules inside. Within RIDFT [90,91] or, perhaps, (MA)RI-MP2 methods [92] in Turbomole this is still feasible - yet we are still waiting for the first results of comptations of this kind.

While we used up to def-TZVPP atomic basis set [29] for complex molecule atoms, to the hydration sphere water molecule we assigned the def-SVP [30,100] atomic basis set [90] only, to keep the computation time realistic.

For accurate description of the explicit solvation, the dispersion interactions and correlation energy are crucial. Yet, the empirical dispersion corrected DFT-D3 was used [93], but later we should try comparison with e.g. MP2, MP2(F12) or MP4, MP4(F12) methods for supramolecular complexes of smaller to higher size.

\subsubsection{Quantum chemical estimation of spectroscopical properties}

All 3N-6 vibrational modes for both singlets ground state and the first excited triplet state can be calculated via GF method [94] from the ground and excited state Hessian matrix (i.e. matrix of all second derivatives of electronic energy with the respect to nuclear coordinates). While we were interested here mere in the one or two modes most closely resembling the symmetric stretching of the uranyl central group (with frequency $\omega_{g s}$ and $\omega_{e s}$ - for the ground and excited state respectively), the other modes may play significant role in the luminescence and absorption spectra shape prediction as well (through the Franck-Condon factors [45-50]).

For the free uranyl ion, $\mathrm{UO}_{2}{ }^{2+}$, for example, the symmetric mode stretching frequency $\omega_{y}$ in electronic state $y \in\{$ gs,es $\}$ equals ${ }^{\mathrm{bb}}$,

$$
\omega_{y}=\sqrt{\frac{1}{\mu} \frac{\partial^{2} E_{y}}{\partial R^{2}}},
$$

Where $E_{y}$ is electronic energy and in case $R$ is average of both U-O bond lengths, the reduced mass $\mu$ equals double $^{\mathrm{cc}}$ of the oxygen nuclear mass (under assumption oxygen nuclear masses equals). Let as define the adiabatic excitation energy $T_{a}$ as a difference of minima $E_{e s, \min }=\min _{R} E_{e s}(R)=E_{e s}\left(R_{e s, \min }\right)$ on the excited state

aa 30 to 40 water molecules depending on the particular complex species.

${ }^{\mathrm{bb}}$ Under the assumption that the two equilibrium U-O bond lengths are identical for given electronic state (i.e. the linear uranyl ion has a center of symmetry in uranium nuclei for both electronic states in question). The assumption is well fulfilled for both bare and coordinated uranyl. potential energy surface (PES, $\left.E_{e s}(R)\right)$ and the ground state PES minima $E_{g s, \min }=\min _{R} E_{g s}(R)=E_{g s}\left(R_{g s, \min }\right)$,

$$
T_{a}=E_{e s, \min }-E_{g s, \min }
$$

The 0 ' $\rightarrow 0$ transition energy $T_{00}$ is connected to the adiabatic excitation energy as

$$
\begin{aligned}
T_{00} & =\left(E_{e s, \min }+Z P E_{e s}\right)\left(-E_{g s, \min }+Z P E_{g s}\right), \\
& =T_{a}+Z P E \Delta
\end{aligned}
$$

where $Z P E_{y}=\frac{1}{2} \sum_{n=1}^{3 N-6} \omega_{y, n}$ is the zero-point energy in the electronic state y.

Vertical excitation energy is defined as a difference between excited state energy and ground state energy both at the same geometry $R_{g s, \min }$ corresponding to the ground state equilibrium,

$$
T_{v, e x}=E_{e s}\left(R_{g s, \min }\right)-E_{g s}\left(R_{g s, \min }\right),
$$

roughly, this energy corresponds to the highest peak maximum position in the absorption spectrum.

Vertical deexcitation energy is defined analogically as an electronic states energy difference at the excited state equilibrium geometry $R_{e s, \min }$,

$$
T_{v, d}=E_{e s}\left(R_{e s, \min }\right)-E_{g s}\left(R_{e s, \min }\right)
$$

roughly corresponding to the peak maximum position of the highest peak in the luminescence/emission spectrum.

The shape of the luminescence and absorption spectra are determined by Franck-Condon factors, which are function of vibrational frequencies in the both electronic states and the difference of equilibrium geometries in the excited and the ground state,

$$
\Delta R=R_{\overline{e s, \min }} R_{g s, \min },
$$

and mutual orientation of excited and ground state $3 \mathrm{~N}-6-$ tuples or normal mode vectors, for bare uranyl group, this reduce to the difference of $\mathrm{U}-\mathrm{O}$ equilibrium bond lengths in excited and ground state (formula (45) without vector arrows). From spectral data, we can fit only the absolute value, $|\Delta R|$, but all reasonable theoretical calculations suggest, that $\Delta R>0$, i.e., the uranyl group bond is elonged due to the electronic excitation (in accordance with the fact, that excitation populate the non-bonding $\mathrm{LUMO}^{\mathrm{dd}}$

In case we work in normalized coordinates,
$R=\frac{1}{\sqrt{2}}\left(\left(r_{O(1)}-r_{U}\right)-\left(r_{O(2)}-r_{U}\right)\right) \frac{1}{\sqrt{2}}=\left(\begin{array}{ll}r_{O(1)} & \left.r_{O(2)}\right)-\end{array}\right.$

i.e. $\sqrt{2}$ - multiplied $R$ considered in the text, the reduced mass has to be half of that considered in the text, i.e. the oxygen nuclear mass.

${ }^{\text {dd }}$ lowest unoccupied molecular orbital, en.wikipedia.org/wiki/HOMO/LUMO 
from bonding $\mathrm{HOMO}^{\mathrm{ee}}$ and therefore decrease effective bond order).

The spectral norm (i.e. the overall luminescence or absorbance of unit concentration), not just the shape of the spectra, represented in case of luminescence by $\mu_{m}$ factor is proportional to the electronic transition probability,

$$
\Gamma=\frac{2 \pi \rho}{\Gamma}\left|\left\langle\psi_{e s}(r)|\hat{T}| \psi_{g s}(r)\right\rangle\right|^{2},
$$

where $\rho$ is energy density of emitted or absorbed el.mag. field, the transition operator $\hat{T}$ commute with the spin operators and therefore, for pure triplet-singlet radiative transition has exactly zero probability $\Gamma=0$, i.e. is forbidden. We cannot compute $\Gamma$ or $\mu_{m}$ within the scalarrelativistic description. When spin-orbit effects are taken into account, the excited state will have also a small singlet admixture (and the ground state similarly even smaller triplet admixture) allowing for non-zero $\Gamma$ (equal to the matrix element between the singlet components of both states plus triplet-triplet part). We plan to exploit the DIRAC program [88] capabilities to calculate $\Gamma$ in further studies.

The widths or width-parameters of individual peaks in spectra might be determined (but were not yet) by two different methodics -

1. By an exhaustive search of all possible supramolecular configurations and the corresponding ground state PES minima (and to them closest lying excited PES minima) and subsequent Boltzmannfactor weighted averaging of the obtained results (spectral peaks for individual configuration might be lorentzian with natural width and possible scaled Doppler Gaussian broadening)

2. By molecular dynamics (MD) study (calculating vertical excitation energy along MD trajectory in the ground state for absorption spectrum and vertical deexcitation energy along MD trajectory in the excited state for luminescence spectrum).

Inclusion of non-adiabatic coupling in "2." (MD study in excited state) may allow for non-quenched luminescence life-time estimation as well. Incorporation of "full molecular dynamics" treating electrons and (light) nuclei on equal footing would allow for modelling of the quenching process and determination of $k_{q}$ (or in particular $A_{q}$ and $\left.E_{A, q}\right)$ values as well. The luminescence life-time modelling would be an ambitious plan even for far future.

\subsubsection{Quantum chemical estimation of thermodynamic properties}

The calculation is based on partition sum $Q$ based statistic physics prediction for Helmholtz energy $F$, entropy $S$ and internal energy $U$ of an ideal-gas-like system of $N$ identical supramolecular complexes [95]

$$
F=-k_{B} T \ln Q
$$

${ }^{\mathrm{ee}}$ highest occupied molecular orbital

$$
\begin{aligned}
U & =k_{B} T^{2}\left(\frac{\partial \ln Q}{\partial T}\right)_{V}, \\
S & =(U-F) / T,
\end{aligned}
$$

where $k_{B}$ is Boltzman constant and $T$ thermodynamic temperature. From the definition of standard molar reaction properties and neglecting the change of $p V$ (pressure $\mathrm{x}$ volume product) in course of chemical reaction (then $\Delta G^{\circ}=\Delta F^{\circ}, \Delta H^{\circ}=\Delta U^{\circ}$ ) we can write

$$
\begin{aligned}
\Delta G^{o} & =E_{0} \Delta \quad Z P E+\Delta G_{v i b}+R T\left(\ln N_{A} \Delta 1\right)+n \\
\Delta H^{o} & =E_{0} \Delta+H_{v i b}, \\
\Delta S^{o} & =\left(\Delta H^{o}-\Delta G^{o}\right) / T
\end{aligned}
$$

when in (50)-(51) using usual simplifications electronically excited states are not populated under investigated temperatures, Born-Oppenheimer approximation, rigid rotor and harmonic oscillator description for vibrational motions. Contribution of rotational and translational degrees of freedom of supramolecular complexes to partition sums ${ }^{\text {ff }}$ are neglected as well. Quantities on right sides of (50) and (51) are defined below for general chemical reaction with stochiometric coefficients $v_{i}$ (negative for reactants, index $i$ correspond to chemical species in the reaction)

$$
\Delta X=\sum_{i} v_{i} X_{i}
$$

with $X$ standing for $E_{0}$ (ground state electronic energy in equilibrium geometry (of $i$-th species, this index is suppressed in the later text)), ZPE (zero-point vibrational energy in the ground electronic state), $G_{v i b}$ (vibrational contribution to $\Delta G^{\circ}$, (54) below), $H_{v i b}$ (vibrational contribution to $\Delta H^{\circ}$, (55) below),

$$
\begin{aligned}
& G_{v i b}=R T \sum_{n} \ln \left(1-\exp \left(-x_{n}\right)\right), \\
& H_{v i b}=R T \sum_{n} \frac{x_{n} \exp \left(-x_{n}\right)}{1-\exp \left(-x_{n}\right)},
\end{aligned}
$$

with

$$
x_{n}=\frac{\omega_{n}}{k_{B} T},
$$

where $n$ index the vibrational modes of $i$-th species, $\omega_{n}$ is the corresponding vibrational frequency.

When we take $X=1$, the $\Delta X$ corresponds to the change of the number of moles in the reaction, $\Delta n$. The last term in (50) is a result of $Q=q^{\mathrm{N}} / N$ ! for partition sum $Q$ of $N$ indistinguishable systems, each with partition $\operatorname{sum} q$, for the case $N=N_{A}$ (Avogadro constant).

The general idea was to consider either the complexation reaction

\footnotetext{
${ }^{\mathrm{ff}}$ since the corresponding motions are partly blocked in liquid matter and the contributions would vanish in limit of complex specie surrounding solvent molecules number $\rightarrow \infty$
} 


$$
\begin{aligned}
& {\left[\mathrm{UO}_{2}\left(\mathrm{H}_{2} \mathrm{O}\right)_{5}\right]^{2+} \cdot r_{1} \mathrm{H}_{2} \mathrm{O}+n \mathrm{XO} \mathrm{O}_{u}^{2-} \cdot r_{2} \mathrm{H}_{2} \mathrm{O}} \\
& {\left[U O_{2}\left(\kappa^{\alpha}-X O_{u}^{2-}\right)_{n}\left(H_{2} O\right)_{K-A}\right]^{2(1-n)} \cdot r_{k} H_{2} O,(57)} \\
& +\Delta r \mathrm{H}_{2} \mathrm{O} \\
& \text { or } \\
& {\left[\mathrm{UO}_{2}\left(\mathrm{H}_{2} \mathrm{O}\right)_{5}\right]^{2+} \cdot \mathrm{s}_{1} \mathrm{H}_{2} \mathrm{O}+n \mathrm{HXO}_{u}^{-} \mathrm{r}_{2} \mathrm{H}_{2} \mathrm{O}} \\
& {\left[\mathrm{UO}_{2}\left(\kappa^{\alpha}-\mathrm{XO}_{u}^{2-}\right)_{n}\left(\mathrm{H}_{2} \mathrm{O}\right)_{K-A}\right]^{2(1-n)} \cdot s_{k} H_{2} \mathrm{O}} \\
& +\Delta s \mathrm{H}_{2} \mathrm{O} \cdot \quad n \mathrm{H}_{3} \mathrm{O}^{+} \quad \mathrm{pH}_{2} \mathrm{O}
\end{aligned}
$$

The latter consider as a reactant protonated ligand $\mathrm{HXO}_{u}^{-}$ $(\mathrm{X}=\mathrm{S}, \mathrm{Se}(u=4), \mathrm{X}=\mathrm{C}(u=3))$ to avoid multiply charged anion computation (which demands peculiar atomic basis with enough diffuse functions due to loosely bounded HOMO electrons) at least for the case $n=1$. The number of explicitly accounted hydration water molecules in supramolecules in (57) and (58) have to fulfil

$$
\begin{aligned}
& r_{k}=r_{1}+n r_{2}+5 \quad K-A+r, \\
& s_{k}=s_{1}+n\left(s_{2}-p\right)+5 \quad K-A+s,
\end{aligned}
$$

where $K$ is the coordination number of uranyl in complex, $A=n_{1}+2 n_{2}$ is number of donor atoms of all ligands ${ }^{\mathrm{gg}}, n$ $=\left(n_{1}, n_{2}\right)$ are numbers of monodentate- and bidentate- (Fig. 7) coordinated ligands ${ }^{\mathrm{u}}\left(n=n_{1}+n_{2}\right)$. The $\Delta r \mathrm{H}_{2} \mathrm{O}$ and $\Delta s$ $\mathrm{H}_{2} \mathrm{O}$ stands for one supramolecule of $\Delta r$ water molecules, i.e. the stechiometric coefficients in (57) and (58) are (-1, $-n, 1,1)$ and $(-1,-n, 1,1,1)$ respectively. While in the limit of all $r_{j}$ or $s_{j} \rightarrow \infty$, their particular ratio should not matter, for finite, computation-feasibly small values of $r_{j}, s_{j}$, their ratio will be important. We suggest to compute „correction to artificial surface tension change" (in the modelled water droplets around the species of interest) by subtracting thermodynamic property of chemical reaction where only surrounding water molecules are considered (without the solute). To minimize this correction, the $r_{j}$ or $s_{j}$ should be for $n=1$ chosen as equal and for $n>1$ we should divide the $\Delta r$ into $n$ equal portions to compute the reaction with the equal number of supramolecular complexes of equal size on each reaction side.

The stability constants are related to the molar standard reaction gibbs functions as

$$
\ln \beta_{m}^{o}=-\Delta G_{m}^{o} / R T .
$$

The $\Delta G^{\circ}$ for the reaction (58) is related to $\Delta G^{\circ}$ for (57) as

$$
\Delta G_{57}^{o}=G_{58}^{o} \Delta+G_{2}^{o},
$$

where $\quad \Delta G_{2}^{o}=\exp \left(K_{2} / R T\right), \quad K_{2} \quad$ being second dissociation constant of $\mathrm{H}_{2} \mathrm{XO}_{\mathrm{u}}$ acid (adopted from literature/experimental data).

\subsection{UV-VIS spectrophotometry}

For spectrophotometric measurements $0.25 \mathrm{M} \mathrm{UO}_{2}{ }^{2+}$ in $0.42 \mathrm{M} \mathrm{HClO}_{4}$ solution (prepared by dissolving solid $\mathrm{UO}_{3}$ (p.a., depleted, n.p. Brno (Chemapol, PrahaCzechoslovakia), $\geq 98 \%$ ) in conc. $\mathrm{HClO}_{4}$ and subsequent demi-water dilution) have been used. $\mathrm{Na}_{2} \mathrm{SO}_{4}$ and $\mathrm{Na}_{2} \mathrm{SeO}_{4}$ as a ligand sources, $\mathrm{NaClO}_{4} \cdot \mathrm{H}_{2} \mathrm{O}$ (all three - p.a., Sigma-Aldrich, $\geq 98 \%$ ) to adjust ionic strength, $1 \mathrm{M}$ $\mathrm{HClO}_{4}$ (by dilution of $60 \%$ p.a., Fluka) to adjust $\mathrm{pH}$ and demineralized water (Milipore, Direct-Q UV3, 18.2 $\mathrm{M} \Omega . \mathrm{cm}\left(25^{\circ} \mathrm{C}\right)$ ).

For uranyl-selenate system spectrophotometric measurement, higher purity $\mathrm{HClO}_{4}$ has been used (SigmaAldrich, $70 \%$ conc., $\geq 99.999 \%$ purity, SHBB3741).

The measurements were done by Varian (Cary 100 Conc) spectrophotometer (Fig. 8) in wavelength range $381-481 \mathrm{~nm}$ (step $1 \mathrm{~nm})$ for temperature $(23.4 \pm 0,5){ }^{\circ} \mathrm{C}$ (uranyl-sulfate system) and temperatures $17.5^{\circ} \mathrm{C}, 20.0^{\circ} \mathrm{C}$, $22,5^{\circ} \mathrm{C}, \ldots, 35^{\circ} \mathrm{C} ; 40^{\circ} \mathrm{C} ; 45^{\circ} \mathrm{C}\left( \pm 0,5^{\circ} \mathrm{C}\right)$ (uranyl-selenate sys.). The cuvette holder (Varian) was thermostated by the Peltier effect.

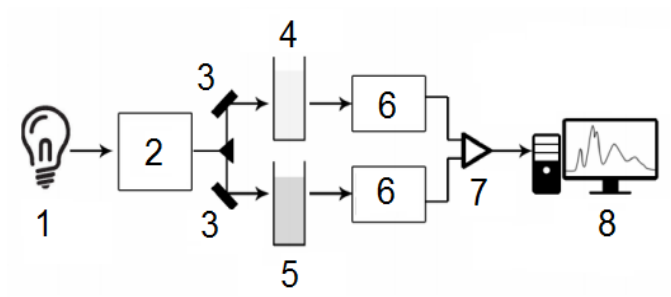

Fig. 8. The UV-vis absorption (spectrophotometric) measurement system. 1 - electromagnetic radiation source, 2 monochromator, 3 - beam splitter, 4 - reference cuvette, 5 cuvette with the measured solution, 6 - detector, 7 -amplifier, 8 - signal processing unit.

\subsection{TRLFS spectroscopy}

For TRLFS measurements, the same chemicals as for spectrophotometry has been used, but the sodium salts were of higher purity ( $\geq 99.99 \%$, Sigma-Aldrich).

The measuring system is described in Figure 9, the laser (2) generates $1064 \mathrm{~nm}$ pulses with $4 \mathrm{~ns}$ duration and $10 \mathrm{~Hz}$ repetition frequency. Excitation pulse output wavelength $266 \mathrm{~nm}$ was generated by double frequency dubling on crystals with $\chi(2)$ non-linearity (SHG $532 \mathrm{~nm}$, SHG $266 \mathrm{~nm}$ ). The $600 \mathrm{~mm}^{-1}$ optical grid (spectral range $163 \mathrm{~nm})(7)$ have been centred at $510 \mathrm{~nm}$. The ICCD camera integration time was set $\Delta t=10 \mu \mathrm{s}$.

The uranyl-sulfate system was measured for ionic strength $I_{M}=0.3 \mathrm{~mol} \cdot \mathrm{dm}^{-3}$ for $T=18^{\circ} \mathrm{C}$ and $p H=2$, further details can be seen in (bakalarka).

For the uranyl-selenate system measurements for ionic strength $I=1.1 \mathrm{~mol} \cdot \mathrm{Kg}_{\mathrm{w}}{ }^{-1}$ were done in Prague at Department of Nuclear Chemistry, energy of the excitation

\section{Experimentals}

\footnotetext{
${ }^{\mathrm{gg}}$ except for water
} 
pulses was $^{\text {hh }} 1.6 \pm 0.2 \mathrm{~mJ}$, excitation wave-length $\lambda_{\text {exc }}=$ $415 \mathrm{~nm}$. Measurements for ionic strength $I=0.05$ $\mathrm{mol} \cdot \mathrm{Kg}_{\mathrm{w}}{ }^{-1}$ were done in INP Orsay in collaboration with Dr. Vladimir Sladkov, excitation wave-length was $430 \mathrm{~nm}$ and average pulse energy $E=(4.0 \pm 0.5) \mathrm{mJ}$ (energy of individual pulses was not measured in this case).

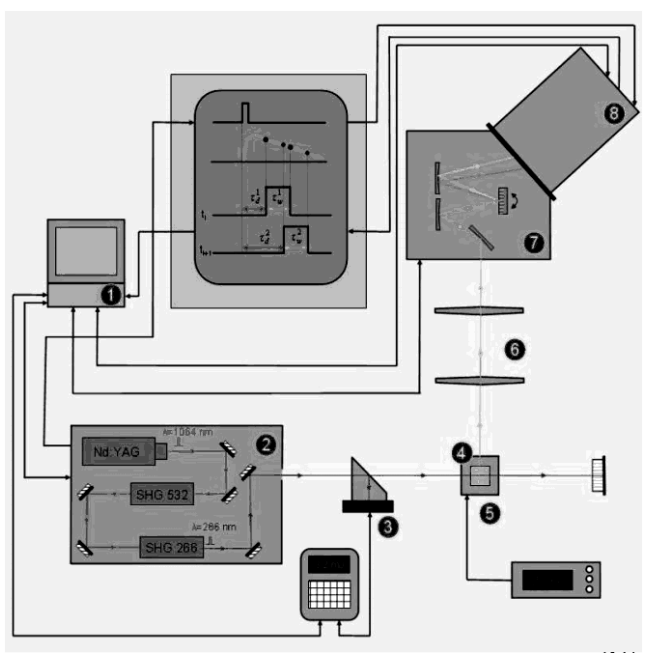

Fig. 9. The TRLFS measurement system stationed at Prague, Nuclear Chemistry Department. 1 - PC control unit, 2 - tunable Nd:YAG laser pumped laser system VIBRANT ${ }^{\mathrm{TM}} 355$ II, $3-$ beam splitter diverting defined part of the beam into digital timeresolved joulemeter FieldMax II, which records individual pulses energies and the 1 synchronize the information with the CCD camera measurement results, 4 - quartz cuvette (SUPRASIL) with the solution in thermostated holder (5). 6 - collimating lenses, 7 - Spectrograph MS257TM, dispersion element (optical grid), 8 - ICCD camera ANDOR iStar with time resolution.

\section{Experimental results}

\subsection{UV-VIS spectrophotometry, uranyl - selenate}

For the uranyl-sulfate system, please see [7] and [96,36], where values of stability constants have been corrected.

Uranyl-selenate system has been measured for relatively high ionic strength $I=(3.8 \pm 0.3) \mathrm{mol} \cdot \mathrm{Kg}_{\mathrm{w}}{ }^{-1}$ in order to allow for $\mathrm{SeO}_{4}{ }^{2-}$ ligand analytical/total concentrations up to $1.36 \mathrm{~mol} \cdot \mathrm{Kg}_{\mathrm{w}}{ }^{-1}$ opening the possibility of tris(selenate)uranyl, $\mathrm{UO}_{2}\left(\mathrm{SeO}_{4}\right)_{3}{ }^{4-}$, to be first time studied. $\mathrm{pH}$ of the 20 measured solutions varied from 1.6 to 2.5 (but was measured with error less than 0.05 for each solution). The wave-length range was $350-500 \mathrm{~nm}$ (step $0.5 \mathrm{~nm}$ ).

The normalized individual component absorption spectra (Fig. 10) show typical bathochromic shift with the respect to the increasing number of $\mathrm{SeO}_{4}{ }^{2-}$ coordinated to the central uranyl group. The speciation diagram (Fig. 11) presents molar concentrations of individual spectral active species as a function of ligand $\left(\mathrm{SeO}_{4}{ }^{2-}\right)$ total molality.

${ }^{\text {hh }}$ The variability of $0.2 \mathrm{~mJ}$ is a result of laser power variation, but energy of each pulse has been measured with roughly ten times higher precision.

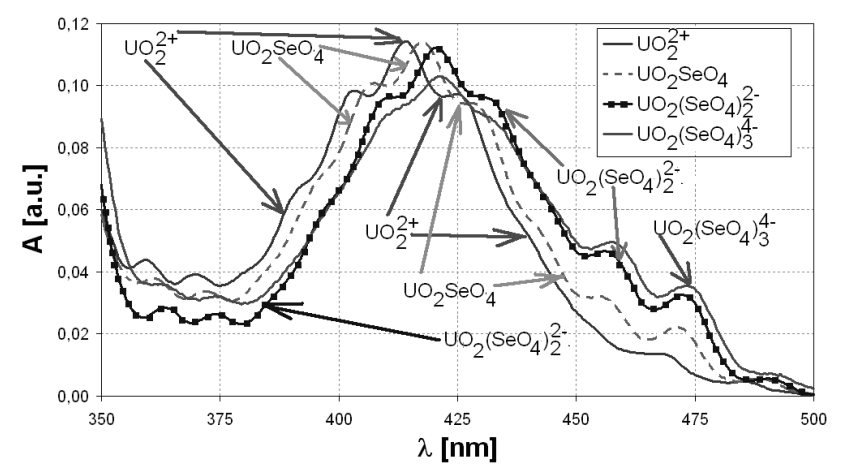

Fig. 10. The normalized ${ }^{\text {ii }}$ individual component absorption spectra for $25^{\circ} \mathrm{C}$ derived by PCA-based data analysis of complex solution spectra for uranyl-selenate system.

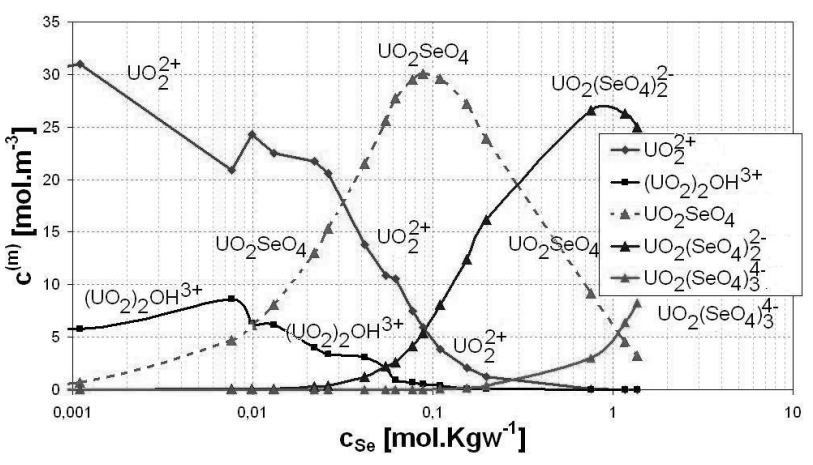

Fig. 11. The model speciation diagram for the fitted (Tab. 1) stability constants for $25^{\circ} \mathrm{C}$.

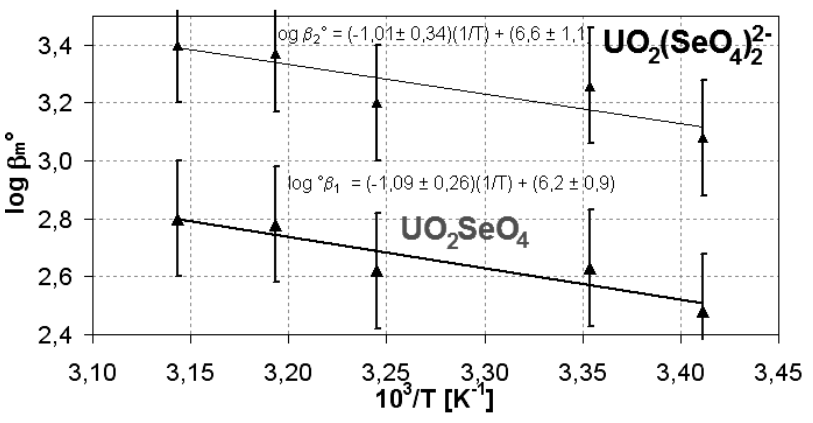

Fig. 12. The Van't Hoff equation fitted thermodynamic stability constants temperature dependence.

By fitting the thermodynamic stability constants (Tab. 1) to Van't Hoff equation (Fig. 12), complexation standard enthalpies and entropies were derived (Tab. 2).

Shapes of absorption spectra for $\mathrm{UO}_{2}\left(\mathrm{SeO}_{4}\right)_{\mathrm{m}}{ }^{2-2 \mathrm{~m}}$ and $\mathrm{UO}_{2}\left(\mathrm{SO}_{4}\right)_{\mathrm{m}}{ }^{2-2 \mathrm{~m}}$ are identical within the measurement error (for given value of $m$ ), e.g. the Fig. 13 shows similarity between $\mathrm{UO}_{2} \mathrm{SeO}_{4}$ and $\mathrm{UO}_{2} \mathrm{SO}_{4}$ absorption spectra shapes. (In spectral region of highest absorption $(380-440 \mathrm{~nm}$ ), different measurements $[5,68]$ of $\mathrm{UO}_{2} \mathrm{SO}_{4}$ differ from each other more than they differ from $\mathrm{UO}_{2} \mathrm{SeO}_{4}$ [36], for $\lambda>$ $440 \mathrm{~nm}$ the S-Se difference can be explained by expanded measurement uncertainties as well).

\footnotetext{
${ }^{\text {ii }}$ With the respect to the standard euclidean norm (25), here without the $N$ in denominator.
} 


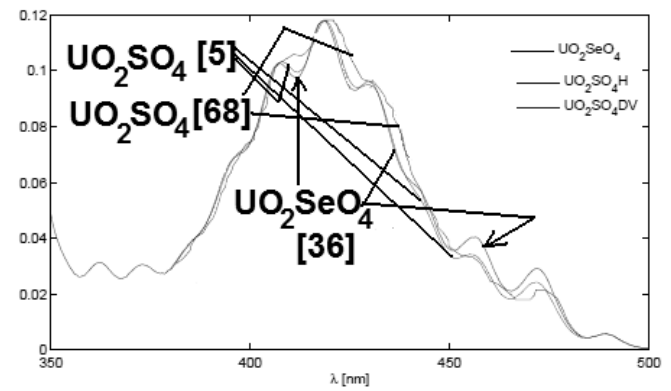

Fig. 13. Comparison between $\mathrm{UO}_{2} \mathrm{SeO}_{4}$ and $\mathrm{UO}_{2} \mathrm{SO}_{4}$ absorption spectra shows almost identical shapes.

Table 1: Uranyl monoselenate and uranyl biselenate thermodynamic properties for $25^{\circ} \mathrm{C}$. The prime before $\beta$, i..e. ' $\beta$ denote that in this study we subtracted $\log (7 / 5)$ from all stability constants (results from eventual $\left(\mathrm{UO}_{2}\right)_{2} \mathrm{OH}^{3+}$ neglection a posteriori), for uncorrected values see the first column in the Tab. 2 .

\begin{tabular}{|c|c|c|c|c|c|c|}
\hline & \multicolumn{3}{|c|}{ This study } & \multicolumn{3}{c|}{ study $^{19}$} \\
\hline $\log { }^{\circ} \beta_{1}{ }^{\circ}$ & 2,48 & \pm & 0,20 & 2,38 & \pm & 0,06 \\
\hline $\log { }^{`} \beta_{2}{ }^{\circ}$ & 3,11 & \pm & 0,10 & 3,70 & \pm & 0,15 \\
\hline$\Delta \mathrm{H}_{1}{ }^{\circ}\left[\mathrm{kJ} \cdot \mathrm{mol}^{-1}\right]$ & 20,9 & \pm & 5,0 & 20 & \pm & 2 \\
\hline$\Delta \mathrm{H}_{2}{ }^{\circ}\left[\mathrm{kJ} \cdot \mathrm{mol}^{-1}\right]$ & 19,2 & \pm & 6,3 & 31 & \pm & 4 \\
\hline$\Delta \mathrm{S}_{1}{ }^{\circ}\left[\mathrm{J} \cdot \mathrm{mol}^{-1} \cdot \mathrm{K}^{-1}\right]$ & 126 & \pm & 21 & 123 & \pm & 6 \\
\hline$\Delta \mathrm{S}_{2}{ }^{\circ}\left[\mathrm{J} \cdot \mathrm{mol}^{-1} \cdot \mathrm{K}^{-1}\right]$ & 119 & \pm & 17 & 180 & \pm & 15 \\
\hline
\end{tabular}

Table 2: Uranyl monoselenate and uranyl bis(selenate) thermodynamic stability constants for $25^{\circ} \mathrm{C}$.

\begin{tabular}{|l|l|l|}
\hline & This study & {$[11]$} \\
\hline $\log \beta_{1}^{\circ}$ & $2.63 \pm 0.20$ & $2.64 \pm 0.01$ \\
\hline $\log \beta_{2}^{\circ}$ & $3.26 \pm 0.10$ & $\leq 3.4$ \\
\hline
\end{tabular}

\subsection{TRLFS spectroscopy}

\subsubsection{Uranyl-sulfate system for $\mathrm{I}=0.3 \mathrm{~mol} \cdot \mathrm{dm}^{-3}$}

The references in the Table 3 below (summarizing experimental stability constant values) stands for several chemometric methods $[13,97,98]$ for data analysis used in J. Višňák Bachelor project $-1=$ Factor analysis of the luminescence spectra of all solutions in series for the shortest delay between excitation laser pulse and ICCD camera signal accumulation $t_{1}=150 \mathrm{~ns}$ (dentoted FASV $(t$ $\left.\left.=t_{1}\right)\right), 2=$ Factor analysis of the time-resolved spectra of all solutions in series (monoexponential decay supposed, dependence of $\tau_{m, i}$ on $i$-th solution composition allowed, denoted FAČRSV in the thesis), 3 = Parallel factor analysis method (PARAFAC-3), NEA $=$ The tabulated NEA value (the $18^{\circ} \mathrm{C}$ assigned value calculated from $25^{\circ} \mathrm{C}$ assigned NEA value plus Van't Hoff correction based on the $\Delta H^{\circ}$ from PhreeqC PCHatches18.dat database)

Table 3. Concentrational stability constants $\beta_{n}$ for the uranylsulfate complex species $\left[\mathrm{UO}_{2}\left(\mathrm{SO}_{4}\right)_{n}\right]^{2-2 \mathrm{n}}(n=1,2)$ for ionic strength $I=0.3 \mathrm{~mol} \cdot \mathrm{dm}^{-3}$ and temperature $t=25^{\circ} \mathrm{C}$ (recalculated from the $18^{\circ} \mathrm{C}$ measurement results by Van't Hoff equation with standard complexation enthalpies $\Delta H^{\circ}$ from the PhreeqC database - PCHatches18.dat ${ }^{24}$.

\begin{tabular}{|l|l|l|l|l|l|l|}
\hline ref. & \multicolumn{3}{|c|}{$\log \beta_{1}$} & \multicolumn{3}{c|}{$\log \beta_{2}$} \\
\hline 1 & 2.09 & \pm & 0.20 & 3.15 & \pm & 0.40 \\
\hline 2 & 1.84 & \pm & 0.47 & 3.31 & \pm & 0.50 \\
\hline 3 & 2.46 & \pm & 0.15 & 4.13 & \pm & 0.16 \\
\hline NEA & 1.87 & \pm & 0.30 & 2.81 & \pm & 0.34 \\
\hline
\end{tabular}

Experimental spectroscopic properties in temporal (Table 4) and wave-length/wave-number (Table 5, Fig. 14) domains are listed below.

Table 4. Luminescence life-times $\tau_{m}$ ( $\tau_{1}$ corresponds to $\mathrm{UO}_{2}{ }^{2+}$, $\tau_{2}$ to $\mathrm{UO}_{2} \mathrm{SO}_{4}$ and $\tau_{3}$ to $\left.\mathrm{UO}_{2}\left(\mathrm{SO}_{4}\right)_{2}{ }^{2-}\right)$ for ionic strength $I=0.3$ mold $\cdot \mathrm{dm}^{-3}$ and measurement temperature $18{ }^{\circ} \mathrm{C}$ in comparison with the literature data for $25^{\circ} \mathrm{C}$.

\begin{tabular}{|l|l|l|l|l|l|l|l|l|l|}
\hline ref. & \multicolumn{3}{|c|}{$\tau_{1}[\mu \mathrm{s}]$} & \multicolumn{3}{c|}{$\tau_{2}[\mu \mathrm{s}]$} & \multicolumn{3}{c|}{$\tau_{3}[\mu \mathrm{s}]$} \\
\hline 2 & 2.39 & \pm & 0,03 & 4.71 & \pm & 0.03 & 16.0 & \pm & 0.1 \\
\hline 3 & 2.16 & \pm & 0,15 & 4.93 & \pm & 0.02 & 11.4 & \pm & 0.1 \\
\hline 1 & $<3$ & & & 4.7 & \pm & 0.3 & 11.5 & \pm & 0.3 \\
\hline $1 '$ & 2.7 & \pm & 0,3 & 4.3 & & & 11.0 & \pm & 1.0 \\
\hline
\end{tabular}

References in Table 4 are: 2 = FAČRSV [97,13] mean value (mean from $\tau_{m, i}$ over $i$ ), $3=$ PARAFAC-3 value, 1 and l' are tabulated literature data from other authors, 1 stands for $I=0.2 \mathrm{M}, c=0.05 \mathrm{M}$ measurement and $1^{\text {' }}$ for $I$ $=1 \mathrm{M}$ measurement. Since those two measurements doesn't differ much and our ionic strength lies between theirs, we can conclude that luminescence life-times presented in thesis [98] are in good agreement with literature data.

Table 5: Experimental luminescence spectroscopic properties of uranyl-sulfate system $\left(I=0.3 \mathrm{~mol} \cdot \mathrm{dm}^{-3}, t=18^{\circ} \mathrm{C}, \mathrm{pH}=2\right)$.

\begin{tabular}{|c|c|c|}
\hline species & $\begin{array}{c}\omega_{\mathrm{gs}, \mathrm{sym}} \\
{\left[\mathrm{cm}^{-1}\right]}\end{array}$ & $\begin{array}{c}T_{0-0} \\
{\left[\mathrm{~cm}^{-1}\right]}\end{array}$ \\
\hline $\mathrm{UO}_{2}{ }^{2+}$ & $875 \pm 8$ & $20506 \pm 21$ \\
\hline $\mathrm{UO}_{2} \mathrm{SO}_{4}$ & $860 \pm 8$ & $20363 \pm 21$ \\
\hline $\mathrm{UO}_{2}\left(\mathrm{SO}_{4}\right)_{2}{ }^{2-}$ & $854 \pm 8$ & $20274 \pm 21$ \\
\hline
\end{tabular}

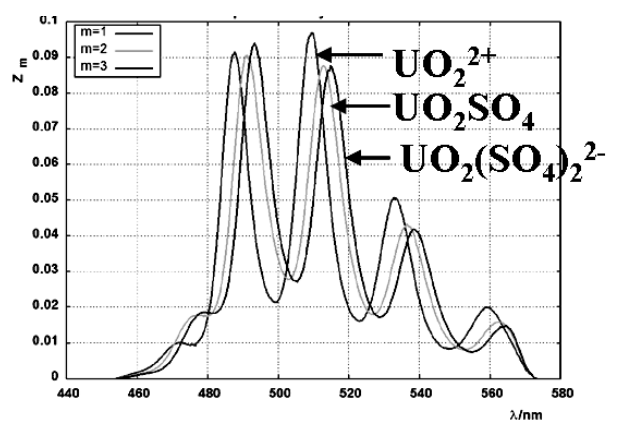

Fig. 14: Uranyl-sulfate system luminescence spectra

4.2.1. Uranyl-selenate system for $\mathrm{I}=0.05 \mathrm{~mol} \mathrm{dm}^{-3}$ and $I=1.1 \mathrm{~mol} \cdot \mathrm{kg}_{\mathrm{w}}^{-1}$

Uranyl - selenate system was investigated experimentally by TRLFS for $I=0.05 \mathrm{~mol} \cdot \mathrm{dm}^{-3}$ ionic strength within $J$. Višňák stay ad IPN Orsay under supervision of Dr. V. 
Sladkov (Tab. $\left.6^{\mathrm{jj}}, 7,[36]\right)$ and for higher ionic strength $I=$ $1.1 \mathrm{~mol} \cdot \mathrm{kg}_{\mathrm{w}}{ }^{-1}$ at Dep. Nucl. Chem., Prague (Fig. 15, for more results in this case [36]).

Table 6. Concentrational stability constants $\beta_{n}$ for the uranylselenate complex species $\left[\mathrm{UO}_{2}\left(\mathrm{SeO}_{4}\right)_{\mathrm{n}}\right]^{2-2 \mathrm{n}}$.

\begin{tabular}{|l|l|l|l|l|l|l|}
\hline \multicolumn{1}{|c|}{$I$} & \multicolumn{3}{c|}{$\log \beta_{1}$} & \multicolumn{3}{c|}{$\log \beta_{2}$} \\
\hline $0.05^{-0}$ & 3.05 & \pm & 0.25 & & & \\
\hline 1.1 & 1.54 & \pm & 0.45 & 1.75 & \pm & 0.50 \\
\hline $1.1^{-0}$ & 2.80 & \pm & 0.50 & 3.0 & \pm & 0.6 \\
\hline$[11]^{-0}$ & 2.64 & \pm & 0.01 & $\leq 3.4$ \\
\hline$[99]^{-0}$ & 2.38 & & 0.06 & 3.70 & \pm & 0.15 \\
\hline
\end{tabular}

Table 7. Experimental luminescence spectroscopic properties of uranyl-selenate system $\left(I=0.05 \mathrm{~mol} \cdot \mathrm{dm}^{-3}, t=26^{\circ} \mathrm{C}, \mathrm{pH}=2\right)$.

\begin{tabular}{|c|c|c|}
\hline species & $\begin{array}{c}\omega_{g s, s y m} \\
{\left[\mathrm{~cm}^{-1}\right]}\end{array}$ & $\begin{array}{c}T_{0-0} \\
{\left[\mathrm{~cm}^{-1}\right]}\end{array}$ \\
\hline $\mathrm{UO}_{2}{ }^{2+}$ & $870 \pm 10$ & $20470 \pm 20$ \\
\hline $\mathrm{UO}_{2} \mathrm{SeO}_{4}$ & $850 \pm 10$ & $20290 \pm 20$ \\
\hline $\mathrm{UO}_{2}\left(\mathrm{SeO}_{4}\right)_{2}{ }^{2-}$ & $850 \pm 10$ & $20200 \pm 20$ \\
\hline
\end{tabular}

\section{Computationals}

Vast majority of calculations were done in Turbomole V6.5 program. Part of scalar relativistic effects were included via 60 electron Effective Core Potential (ECP) for uranium atom, all other electrons were, at this level of approximation treated as non-relativistic ${ }^{\mathrm{kk}}$. The atomic basis sets used were def-SVP (denoted „S“ in all tables in the section 6 below, $[30,100]$ ) and def-TZVPP (denoted „T", [29,30], for solvated models, for solvent water molecules only def-SVP atomic basis set was used to reduce the computational demands).

For the ground state properties, Hartree-Fock / SelfConsistent Field (SCF) method was used for comparison (as a method not including the electron correlation) and for generation of molecular orbital basis for post-HF wavefunction based methods (MP2, CIS, CC) [81]. First method used was DFT with hybrid functional B3-LYP [28,82-85] and GGA functional B-P [82-87]. The latter in Turbomole V6.5 is implemented also within Resolution of Identity (RI-) approximation [90,91] which further save computational time allowing for larger supramolecular structures to be investigated. The RI-methodology was used in post-HF methods as well. jj The values in rows with ionic strength with upper index "-0" correspond to thermodynamic ("activity defined") stability constants. ${ }_{\mathrm{kk}}$ this excludes the possibility for luminescence life-time and $\mu_{m}$ computational estimation as they are beyond-scalar relativistic effects,

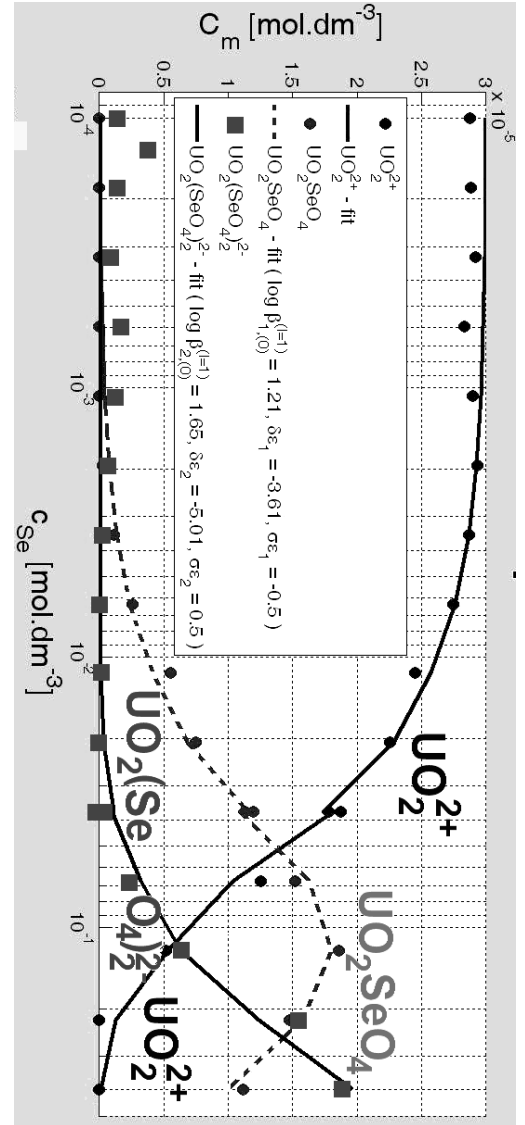

Fig. 15. Speciation diagram for the uranyl-selenate $\left(\mathrm{UO}_{2}{ }^{2+}-\right.$ $\left.\mathrm{SeO}_{4}{ }^{2-}-\mathrm{H}_{2} \mathrm{O}\right)$ system $\left(I=1.1 \mathrm{~mol} \cdot \mathrm{kgw}^{-1}, p H=2\right)$ measured by TRLFS method. Full circles correspond to PCA predicted experimental molar concentrations of uranyl $\left(\mathrm{UO}_{2}^{2+}\right)$, uranyl monoselenate $\left(\mathrm{UO}_{2} \mathrm{SeO}_{4}\right)$ and uranyl bis(selenate) $\left(\mathrm{UO}_{2}\left(\mathrm{SeO}_{4}\right)_{2}{ }^{2-}\right.$ ). The diagram has been exported as screenshot from Matlab [105] routine written by A. Vetešník from J. Višňák’s algorithm.

For DFT calculations the D3 dispersion correction was applied [93]. Except few chosen cases which are denoted by subscript "-D" in section 6 Tables.

The ref. 9 in Table 8 " $4 \mathrm{cDFT} / 2 \mathrm{z}$ " stands for allelectron four component Dirac equation-based DFT/B3LYP within Dyall double-zeta atomic basis set [101] for bare $\mathrm{UO}_{2}{ }^{2+}$ done in the DIRAC 13 program [88].

All figures have been exported from Molden [104] screenshots.

\section{Quantum chemical calculation results}

\subsection{Uranyl, $\mathrm{UO}_{2}{ }^{2+}$}

For the uncoordinated uranyl, we present results for the computed ground state properties for bare $\mathrm{UO}_{2}{ }^{2+}$ group (Tab. 8), for the hydrated form - pentaaquauranyl complex $\left[\mathrm{UO}_{2}\left(\mathrm{H}_{2} \mathrm{O}\right)_{5}\right]^{2+}$ (Table 9) and for certain explicit hydrated supramolecules $\left[\mathrm{UO}_{2}\left(\mathrm{H}_{2} \mathrm{O}\right)_{5}\right]^{2+} . n \mathrm{H}_{2} \mathrm{O}$ (Table 10). For the respective lowest lying excited triplet state properties, please see Tables 11-15.

but can be a good starting point for equilibrium geometry, vibrational frequency and hydration estimation 
The bare $\mathrm{UO}_{2}{ }^{2+} \mathrm{SCF}$ and DFT calculations were supplemented ${ }^{11}$ by 3 -fragment counterpoise BSSE correction in the equilibrium geometry (single point BSSE calculation), where fragments were the individual atoms and were assigned by charge number +2 for uranium atom and 0 for oxygens ${ }^{\mathrm{mm}}$.

The results for the $\mathrm{CC} 2$ method are not presented, since, in agreement with previous studied done by others on, e.g. ozone molecule, this method is unsuitable for equilibrium geometry determination.

Table 8. Bare $\mathrm{UO}_{2}{ }^{2+}$ ground state properties. The molecule is predicted to be linear by all methods below.

\begin{tabular}{|c|c|r|c|c|r|}
\hline $\begin{array}{c}\mathrm{re} \\
\mathrm{f}\end{array}$ & $\begin{array}{c}\text { method } \\
\text { basis }\end{array}$ & $\begin{array}{c}\omega_{\text {sym }} \\
{\left[\mathrm{cm}^{-1}\right]}\end{array}$ & $\begin{array}{c}\mathrm{R}_{\min } \\
{[\mathrm{pm}]}\end{array}$ & $\begin{array}{c}\mathrm{E}-\mathrm{E}_{\text {ref }} \\
{[\text { hartree }]}\end{array}$ & $\begin{array}{c}\Delta \mathrm{E}_{\text {BSSE }} \\
{\left[10^{-3}\right.} \\
\text { hartree }]\end{array}$ \\
\hline 1 & $\mathrm{~B} 3 \mathrm{LYP} / \mathrm{S}$ & 1049.7 & 169.6 & 0.17730 & 16.12 \\
\hline 2 & $\mathrm{~B} 3 \mathrm{LYP} / \mathrm{T}$ & 1044.1 & 169.3 & 0.00000 & 0.69 \\
\hline 3 & $\mathrm{~B}-\mathrm{P} / \mathrm{S}$ & 992.1 & 171.3 & -0.19203 & 16.24 \\
\hline 4 & $\mathrm{~B}-\mathrm{P} / \mathrm{T}$ & 986.8 & 171.1 & -0.36726 & 1.87 \\
\hline 5 & $\mathrm{SCF} / \mathrm{S}$ & 1243.3 & 164.4 & 2.45459 & 9.43 \\
\hline 6 & $\mathrm{SCF} / \mathrm{T}$ & 1240.3 & 163.9 & 2.26490 & -0.04 \\
\hline 7 & $\mathrm{MP} / \mathrm{S}$ & 938.2 & 172.8 & 1.63834 & \\
\hline 8 & $\mathrm{MP} 2 / \mathrm{T}$ & 943.9 & 171.5 & 1.31395 & \\
\hline 9 & $4 \mathrm{cDFT} / 2 \mathrm{z}$ & & 171.8 & & \\
\hline
\end{tabular}

Supposed linear geometry of central uranyl group was in $\left[\mathrm{UO}_{2}\left(\mathrm{H}_{2} \mathrm{O}\right)_{5}\right]^{2+}$ slightly broken, in particular for the " $\mathrm{C}_{2 \mathrm{v}}$-like" molecular models. The bond angle $\mathrm{yl} \mathrm{O}-\mathrm{U}-\mathrm{O}_{\mathrm{yl}}$ in the uranyl group will be denoted a in all tables below.

Table 9. Pentaaquauranyl $\left[\mathrm{UO}_{2}\left(\mathrm{H}_{2} \mathrm{O}\right)_{5}\right]^{2+}$ in vacuum, ground state properties.

\begin{tabular}{|c|c|c|c|c|c|c|}
\hline & $\begin{array}{c}\bmod \\
\text { el }\end{array}$ & $\begin{array}{l}\text { method } \\
\text { basis }\end{array}$ & $\begin{array}{c}\omega_{\mathrm{sym}} \\
{\left[\mathrm{cm}^{-1}\right]}\end{array}$ & $\begin{array}{c}\mathrm{R}_{\min } \\
{[\mathrm{pm}]}\end{array}$ & $\begin{array}{c}\alpha \\
{\left[{ }^{\circ}\right]}\end{array}$ & $\begin{array}{c}\text { E-E }_{\text {ref }} \\
{[\text { hartree] }}\end{array}$ \\
\hline 1 & $\mathrm{C}_{2 \mathrm{v}}$ & B3LYP/S & 947.7 & 174.6 & 177 & $+102 \mathrm{~cm}^{-1}$ \\
\hline 2 & $\mathrm{D}_{5 \mathrm{~h}}$ & B3LYP/S & 945.0 & 174.7 & 179 & +0.6439 \\
\hline 3 & $\mathrm{C}_{2 \mathrm{v}}$ & B3LYP/T & 946.6 & 174.1 & 177 & $+72 \mathrm{~cm}^{-1}$ \\
\hline 4 & $D_{5 h}$ & B3LYP/T & 946.9 & 174.1 & 180 & 0.0000 \\
\hline 5 & $D_{5 h}$ & $\mathrm{~B}-\mathrm{P} / \mathrm{S}$ & 888.6 & 176.9 & 176 & $+230 \mathrm{~cm}^{-1}$ \\
\hline 6 & $\mathrm{C}_{2 \mathrm{v}}$ & B-P/S & 893.8 & 176.7 & 176 & $+459 \mathrm{~cm}^{-1}$ \\
\hline 7 & $\mathrm{C}_{2 \mathrm{v}}$ & RI-B-P/S & 893.9 & 176.7 & 175 & $+212 \mathrm{~cm}^{-1}$ \\
\hline 8 & $\mathrm{D}_{5 \mathrm{~h}}$ & RI-B-P/S & 888.5 & 176.9 & 176 & +0.05843 \\
\hline 9 & $\mathrm{C}_{2 \mathrm{v}}$ & RI-B-P/T & 892.8 & 176.1 & 176 & $+66 \mathrm{~cm}^{-1}$ \\
\hline $\mathrm{A}$ & $D_{5 h}$ & RI-B-P/T & 892.9 & 176.2 & 180 & -0.576509 \\
\hline B & $\mathrm{C}_{2 \mathrm{v}}$ & $\mathrm{SCF} / \mathrm{S}$ & 1118 & 168.9 & 178 & $+140 \mathrm{~cm}^{-1}$ \\
\hline $\mathrm{C}$ & $\mathrm{D}_{5 \mathrm{~h}}$ & $\mathrm{SCF} / \mathrm{S}$ & 1117 & 169.0 & 180 & +4.78537 \\
\hline $\mathrm{D}$ & $\mathrm{C}_{2 \mathrm{v}}$ & $\mathrm{SCF} / \mathrm{T}$ & 1112 & 168.3 & 178 & $+184 \mathrm{~cm}^{-1}$ \\
\hline $\mathrm{E}$ & $\mathrm{D}_{5 \mathrm{~h}}$ & $\mathrm{SCF} / \mathrm{T}$ & 1119 & 168.3 & 180 & +4.13471 \\
\hline $\mathrm{F}$ & $\mathrm{C}_{2 \mathrm{v}}$ & MP2/S & 887.3 & 177.3 & 177 & $+64 \mathrm{~cm}^{-1}$ \\
\hline G & $\mathrm{C}_{2 \mathrm{v}}$ & $\mathrm{MP} 2 / \mathrm{T}$ & 888.1 & 175.6 & 177 & \\
\hline $\mathrm{H}$ & $\mathrm{D}_{5 \mathrm{~h}}$ & MP2/S & 887.1 & 177.3 & 180 & +2.91340 \\
\hline I & $\mathrm{D}_{5 \mathrm{~h}}$ & $\mathrm{MP} 2 / \mathrm{T}$ & & 176.0 & 180 & +0.91216 \\
\hline
\end{tabular}

\footnotetext{
${ }^{11}$ The BSSE corrections here and in the proceedings contribution below are not included in the listed electronic energies and their differences. ${ }^{\mathrm{mm}}$ Since $\left.\mathrm{O}(0) \equiv \mathrm{U}(2+) \equiv \mathrm{O}(0)\right)$ rounded partial charges are the same for a wide varienty of quantum chemical methods and partial charge determining methodics.

${ }^{\mathrm{n} n} E_{\text {ref }}=E\left(\mathrm{D}_{5 \mathrm{~h}}, \mathrm{~B} 3 \mathrm{LYP} / \mathrm{T}\right)=-1009.20134718$ hartree for the first four rows. Since only computations for the same molecule within same or
}

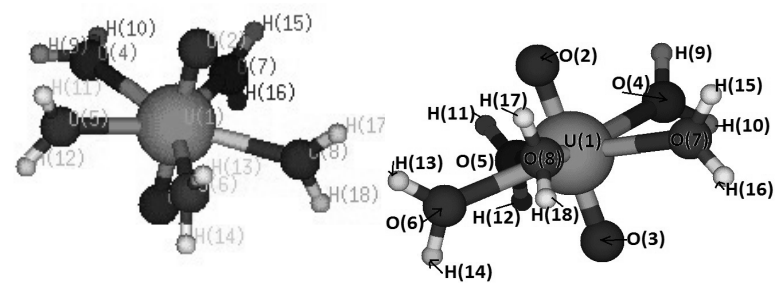

Fig. 16. DFT/B3LYP/defSVP calculations (left) The $\mathrm{C}_{2 \mathrm{v}}$-like molecular geometry, please note the upper left coordinated water molecule $(\mathrm{H}(9)-\mathrm{O}(4)-\mathrm{H}(10))$ which whole lies in the equatorial plane (plane perpendicular to the uranyl group) unlike the four others (which define planes perpendicular to the equatorial one). On right the $\mathrm{D}_{5 \mathrm{~h}}$-like molecular geometry (which is yet found global energy minimum) is depicted - the symmetry group is, in fact lower, supposed pentagon of donor oxygen atoms is deformed, but note that all water molecules are almost perpendicular to the equatorial plane.

The energy difference between the two structures in Figure 16 is between $64 \mathrm{~cm}^{-1}$ and $220 \mathrm{~cm}^{-1}$ depending on the chosen method (Table 9, rightmost column). In the most cases, the $\mathrm{C}_{2 \mathrm{v}}$-like molecular geometries correspond to saddle point with one small imaginary frequency connected to tangential projection of rotation of the specific coordinated water ( $\mathrm{H}(9)-\mathrm{O}(4)-\mathrm{H}(10))$ from the left part of Figure 16 (results of geometry DFT/B3LYP optimization for the small atomic bais set def-SVP). The recalculation in larger basis set def-TZVPP let to the rotation of water molecules for the $\mathrm{D}_{5 \mathrm{~h}}$ structure (Figure 17).

For the explicitly hydrated $\left[\mathrm{UO}_{2}\left(\mathrm{H}_{2} \mathrm{O}\right)_{5}\right]^{2+} . n \mathrm{H}_{2} \mathrm{O}$ structures we started with model preserving the $\mathrm{D}_{5 \mathrm{~h}}$ approximate symmetry ( $n=10$, left in Fig. 18).

The uranyl group vibrational modes for explicitly hydrated structures coupled to other supramolecular vibrational modes, as a result, Table 10 lists only one "typical frequency" and the other modes will be later discussed in the Supplementary Information.
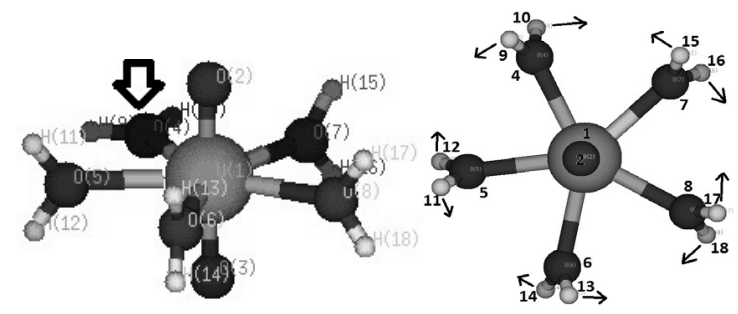

Fig. 17. DFT/B3LYP/defTZVPP equilibrium geometries (left): $\mathrm{C}_{2 \mathrm{v}}$-like model with the water in equatorial coordination plane highlighted by an arrow, (right): top view on $\mathrm{D}_{5 \mathrm{~h}}$-like model showing slight rotation of water molecules with the respect to the ${\mathrm{U}-\mathrm{O}_{\text {water }}}_{\text {axis }}$ - the water planes have dihedrals (like $\mathrm{O}(8)-\mathrm{U}(1)-$ $\mathrm{O}(6)-\mathrm{H}(13)) \quad 68.5-68.9^{\circ}$ instead of $90^{\circ}$ (perpendicular do equatorial plane). similar method are reasonably comparable, the $E_{\text {ref }}$ respectively vary row by row. For clarity, the matching and particular $E_{\text {ref }}$ values will be provided in the Supp. Inf. (values are in Hartree, for values in $\mathrm{cm}^{-1}$ the reference is the value for the same method and same basis given in hartree). 
Table 10: Hydrated Pentaaquauranyl $\left[\mathrm{UO}_{2}\left(\mathrm{H}_{2} \mathrm{O}\right)_{5}\right]^{2+} . n \mathrm{H}_{2} \mathrm{O}$, ground state properties.

\begin{tabular}{|c|c|c|r|r|r|r|}
\hline & $n$ & $\begin{array}{c}\text { method } \\
\text { basis }\end{array}$ & $\begin{array}{c}\omega_{\text {sym }} \\
{\left[\mathrm{cm}^{-1}\right]}\end{array}$ & $\begin{array}{c}\mathrm{R}_{\text {min }} \\
{[\mathrm{pm}]}\end{array}$ & $\begin{array}{c}\alpha \\
{\left[{ }^{\circ}\right]}\end{array}$ & $\begin{array}{c}\text { E-E } \\
{[\text { hartree }}\end{array}$ \\
\hline $\mathbf{1}$ & 10 & B3LYP/S & 888.7 & 177.5 & 178 & 1.6746 \\
\hline 2 & 10 & SCF/S & 1074 & 170.5 & 179 & 9.5488 \\
\hline 3 & 10 & B3LYP/S & 925.8 & 176.2 & 180 & 1.6810 \\
\hline 4 & 10 & SCF/S & 1083 & 170.3 & 180 & 9.5509 \\
\hline $\mathbf{5}$ & 10 & B3LYP/S & 869.7 & 177.2 & 179 & 1.6712 \\
\hline $\mathbf{6}$ & 10 & B3LYP/T & 905.4 & 176.4 & 179 & 1.0832 \\
\hline $\mathbf{7}$ & 10 & B3LYP/T & 927.3 & 175.5 & 180 & 1.0257 \\
\hline 8 & 10 & RI-B-P/S & 837.9 & 179.7 & 178 & 0.6488 \\
\hline $\mathbf{9}$ & $\mathbf{1 0}$ & RI-B-P/T & $\mathbf{8 4 0 . 3}$ & $\mathbf{1 7 9 . 2}$ & $\mathbf{1 7 8}$ & $\mathbf{0 . 0 0 0 0}$ \\
\hline A & 12 & B3LYP/S & 918.1 & 176.5 & 178 & 0.6567 \\
\hline $\mathbf{B}$ & 12 & B3LYP/S & 909.9 & 176.4 & 179 & 0.6682 \\
\hline C & $\mathbf{1 2}$ & B3LYP/T & $\mathbf{9 1 0 . 9}$ & $\mathbf{1 7 6 . 0}$ & $\mathbf{1 7 8}$ & $\mathbf{0 . 0 0 0 0}$ \\
\hline D & 12 & B3LYP/S & 899.2 & 176.5 & 177 & 0.6575 \\
\hline E & 12 & B3LYP/T & 905.0 & 176.9 & 177 & 0.0005 \\
\hline F & 20 & B3LYP/S & 895.4 & 177.5 & 173 & 0.0062 \\
\hline G & 20 & B3LYP/S & 890.9 & 177.6 & 173 & 0.0042 \\
\hline H & $\mathbf{2 0}$ & B3LYP/S & $\mathbf{8 7 6 . 6}$ & $\mathbf{1 7 8 . 1}$ & $\mathbf{1 7 9}$ & $\mathbf{0 . 0 0 0 0}$ \\
\hline I & 20 & B3LYP/S & 908.5 & 176.6 & 179 & 0.1081 \\
\hline J & 20 & B3LYP/S & 890.9 & 177.6 & 173 & 0.0042 \\
\hline K & 20 & SCF/S & 1074 & 170.5 & 179 & 11.6142 \\
\hline L & 20 & B3LYP/T & 893.7 & 177.1 & 173 & -0.6724 \\
\hline M & 55 & RI-B-P/S & 838.1 & 176.6 & 172 & -2.9190 \\
\hline $\mathbf{N}$ & $\mathbf{5 5}$ & B3LYP/S & $\mathbf{9 2 2 . 5}$ & $\mathbf{1 7 5 . 6}$ & $\mathbf{1 7 6}$ & $\mathbf{0 . 0 0 0 0}$ \\
\hline
\end{tabular}

A need to eliminate even the one small imaginary vibrational frequency (Fig. 18) let us to structure with opened rings of solvent water molecules (right in Fig. 18). To close the ring again, $\left[\mathrm{UO}_{2}\left(\mathrm{H}_{2} \mathrm{O}\right)_{5}\right]^{2+} .12 \mathrm{H}_{2} \mathrm{O}$ models with either reflexion plane (Fig. 19, left) or inversion centre (Fig. 19, right) have been adopted. Figure 20 shows the largest structure investigated yet with 55 solvent water molecules.

The two fragment BSSE correction where one fragment are two coordinated water molecules (which will left the coordination sphere in possible reaction leading to $\left.\left[\mathrm{UO}_{2}\left(\kappa^{2}-\mathrm{SO}_{4}\right)\left(\mathrm{H}_{2} \mathrm{O}\right)_{3}\right]\right)$ for $\mathrm{D}_{5 \mathrm{~h}}$-like $\left[\mathrm{UO}_{2}\left(\mathrm{H}_{2} \mathrm{O}\right)_{5}\right]^{2+}$ in vacuum yield $20.26 \mathrm{mH}(53.20 \mathrm{~kJ} / \mathrm{mol})$ and $3.37 \mathrm{mH}(8.84$ $\mathrm{kJ} / \mathrm{mol}$ ) for def-SVP and def-TZVPP atomic basis sets for DFT single-point calculation at the ground electronic state equilibrium geometry.

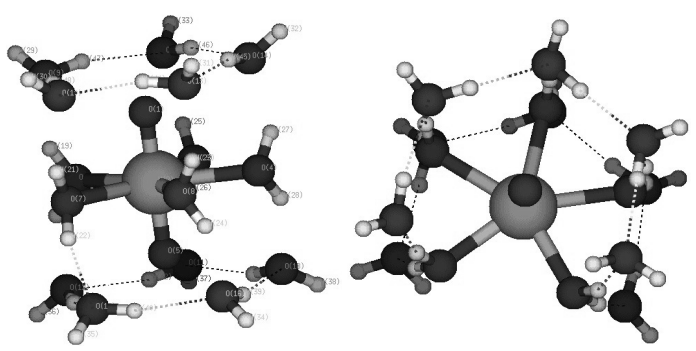

Fig. 18. $\left[\mathrm{UO}_{2}\left(\mathrm{H}_{2} \mathrm{O}\right)_{5}\right]^{2+} \cdot 10 \mathrm{H}_{2} \mathrm{O} \quad \mathrm{DFT} / \mathrm{B} 3 \mathrm{LYP} / \mathrm{T}^{\mathrm{oo}}$ equilibrium geometries, left model (referenced as " 6 " in Tab. 10), resembling $\mathrm{D}_{5}$ geometry corresponds to local stationary point with one imaginary vibrational frequency (ie $23.1 \mathrm{~cm}^{-1}$ ). The right model (,7“" in Tab. 10) has $12.6 \times 10^{3} \mathrm{~cm}^{-1}$ higher energy than the left one and has lower symmetry, but corresponds to true local minimum.

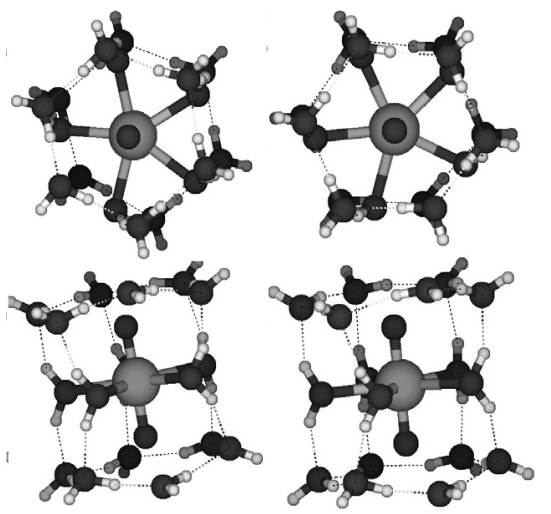

Fig. 19. $\left[\mathrm{UO}_{2}\left(\mathrm{H}_{2} \mathrm{O}\right)_{5}\right]^{2+} \cdot 12 \mathrm{H}_{2} \mathrm{O}$ DFT/B3LYP/T eq. geometries ("C" and " $\mathrm{E}$ " in Tab. 10). While the solute has $\mathrm{D}_{5 \mathrm{~h}}$ symmetry, solvent molecules forms $\mathrm{D}_{6 \mathrm{~h}}$ (left) or $\mathrm{D}_{6}$ (right). The left structure is favoured by $99 \mathrm{~cm}^{-1}$. The prime in frequency value in the respective row „E“ stands for „frozen nuclei“ approximation applied to solvent molecules.

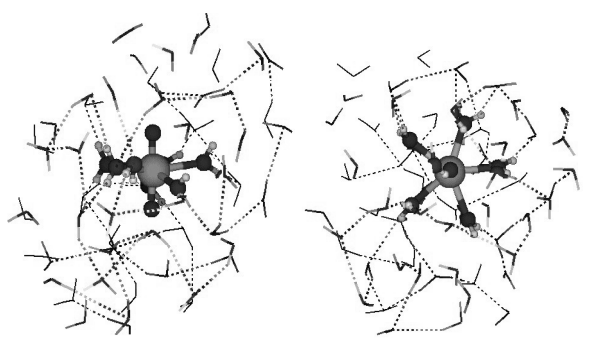

Fig. 20. $\left[\mathrm{UO}_{2}\left(\mathrm{H}_{2} \mathrm{O}\right)_{5}\right]^{2+} .55 \mathrm{H}_{2} \mathrm{O}$ equilibrium geometry (front and top view on supramolecule) for DFT/B3LYP/defSVP method. Initial geometry was generated by Packing [102] from in vacuum optimized pentaaquauranyl, positions for 55 solvent water molecules have been optimized by Turbomole default universal force-filed (solute fixed) and then only solute geometry was optimized by DFT.

For a bare uranyl in vacuum (Table 11), the ordering of the two lowest lying triplet states $\left({ }^{3} \Delta_{\mathrm{g}},{ }^{3} \Phi_{\mathrm{g}}\right)$ is predicted to be $\mathrm{T}_{\mathrm{x}}\left({ }^{3} \Phi_{\mathrm{g}}\right)<\mathrm{T}_{\mathrm{x}}\left({ }^{3} \Delta_{\mathrm{g}}\right)$ by TDDFT while the HartreeFock $(\mathrm{SCF}) / \mathrm{CIS}$ predicts the opposite $\left(\mathrm{T}_{\mathrm{x}}\left({ }^{3} \Phi_{\mathrm{g}}\right)>\mathrm{T}_{\mathrm{x}}\left({ }^{3} \Delta_{\mathrm{g}}\right)\right)$. However, both methods predict the same ordering of symmetric mode vibrational frequencies $\omega_{e s, s y m}$ and electronic excitation induced $\mathrm{U}-\mathrm{O}$ bond elongation $\Delta R$.

Table 11. Excited state spectroscopic properties, bare uranyl, $\mathrm{UO}_{2}{ }^{2+}$, in vacuum. Excitation energies $T$ are in $10^{3} \mathrm{~cm}^{-1}$

\begin{tabular}{|c|c|c|c|c|c|c|}
\hline $\begin{array}{c}\text { method } \\
\text { basis }\end{array}$ & $\begin{array}{c}\omega_{\mathrm{es}, \mathrm{sym}} \\
{\left[\mathrm{cm}^{-1}\right]}\end{array}$ & $\begin{array}{c}\Delta \mathrm{R} \\
{[\mathrm{pm}]}\end{array}$ & $\mathrm{T}_{0,0}$ & $\mathrm{~T}_{\mathrm{v}, \mathrm{ex}}$ & $\mathrm{T}_{\mathrm{v}, \mathrm{d}}$ & state \\
\hline B3LYP/S & 903.9 & 6.2 & 14.6 & 16.8 & 13.3 & ${ }^{3} \Phi_{\mathrm{g}}$ \\
\hline & 927.9 & 4.6 & 17.3 & 18.7 & 16.7 & ${ }^{3} \Delta_{\mathrm{g}}$ \\
\hline B3LYP/T & 903.2 & 6.2 & 14.8 & 17.0 & 13.6 & ${ }^{3} \Phi_{\mathrm{g}}$ \\
\hline & 925.0 & 2.6 & 17.2 & 18.6 & 16.6 & ${ }^{3} \Delta_{\mathrm{g}}$ \\
\hline CIS-HF/S & 1111 & 2.6 & 20.6 & 21.4 & 20.5 & ${ }^{3} \Delta_{\mathrm{g}}$ \\
\hline & 1088 & 3.8 & 25.6 & 26.8 & 25.0 & ${ }^{3} \Phi_{\mathrm{g}}$ \\
\hline CIS-HF/T & 1103 & 2.8 & 20.0 & 23.8 & 19.7 & ${ }^{3} \Delta_{\mathrm{g}}$ \\
\hline & 1085 & 3.8 & 25.2 & 27.8 & 24.5 & ${ }^{3} \Phi_{\mathrm{g}}$ \\
\hline
\end{tabular}

For the pentaaquauranyl, $\left[\mathrm{UO}_{2}\left(\mathrm{H}_{2} \mathrm{O}\right)_{5}\right]^{2+}$, in vacuum, only one lowest lying excited triplet state has been studied. Unlike for the ground state, for the excited state, $\mathrm{C}_{2 \mathrm{v}}$ equilibrium geometry is preferred by $177 \mathrm{~cm}^{-1}\left(389 \mathrm{~cm}^{-1}\right)$

\footnotetext{
${ }^{\circ}$ def-TZVPP AO basis was used for the central complex $\left[\mathrm{UO}_{2}\left(\mathrm{H}_{2} \mathrm{O}\right)_{5}\right]^{2+}$ and def-SVP AO basis for the 10 solvent water molecules.
} 
over the $\mathrm{D}_{5 \mathrm{~h}}$ one due to the TDDFT/defSVP (defTZVPP). However, according to CIS-HF/defSVP the $\mathrm{D}_{5 \mathrm{~h}}$ excited state minimum is by $36 \mathrm{~cm}^{-1}$ lower. In the table 12 the column "Model" shows molecular geometry of the lower and upper electronic states considered and for the excited state also the respective irreducible representation $\left(\mathrm{D}_{5 \mathrm{~h}}\left(1 \mathrm{e}_{2}{ }^{\prime}\right)\right.$ stands for an approximate symmetry, the true symmetry is $\mathrm{C}_{2}(1 \mathrm{a})$ - see Fig. 17 (right)), "55" stands for $\mathrm{D}_{5 \mathrm{~h}} \rightarrow \mathrm{D}_{5 \mathrm{~h}}\left(1 \mathrm{e}_{2}\right.$ '), "22" stands for $\mathrm{C}_{2 \mathrm{v}} \rightarrow \mathrm{C}_{2 \mathrm{v}}\left(1 \mathrm{~b}_{1}\right)$ and " 52 " stands for $\mathrm{D}_{5 \mathrm{~h}} \rightarrow \mathrm{C}_{2 \mathrm{v}}\left(1 \mathrm{~b}_{1}\right)$.

Table 12: Excited state spectroscopic properties, Pentaaquauranyl in vacuum ${ }^{\mathrm{pp}}$.

\begin{tabular}{|c|c|c|c|c|c|}
\hline ref & $\begin{array}{c}\text { method } \\
\text { basis }\end{array}$ & $\begin{array}{c}\mathrm{T}_{0,0} \\
{\left[\mathrm{~cm}^{-1}\right]}\end{array}$ & $\begin{array}{c}\mathrm{T}_{\mathrm{v}, \mathrm{ex}} \\
{\left[\mathrm{cm}^{-1}\right]}\end{array}$ & $\begin{array}{c}\mathrm{T}_{\mathrm{v}, \mathrm{d}} \\
{\left[\mathrm{cm}^{-1}\right]}\end{array}$ & model \\
\hline 1 & \multirow{3}{*}{ B3LYP/S } & 19193 & 20497 & 18459 & 55 \\
\hline 2 & & 19064 & 19993 & 18306 & 22 \\
\hline 3 & & 19284 & 20497 & 18306 & 52 \\
\hline 4 & \multirow{2}{*}{ B3LYP/T } & & 20264 & 18465 & 55 \\
\hline 5 & & & 19803 & 18115 & 22 \\
\hline 6 & \multirow{3}{*}{ CIS-HF/S } & 24254 & 24951 & 24130 & 55 \\
\hline 7 & & 24276 & 24847 & 24038 & 22 \\
\hline 8 & & 24516 & 24951 & 24038 & 52 \\
\hline 9 & \multirow{2}{*}{ CIS-HF/T } & & 24770 & & 55 \\
\hline 10 & & & 24673 & 23785 & 22 \\
\hline 11 & $\mathrm{CIS}(\mathrm{D}) / \mathrm{S}$ & & 19132 & & 55 \\
\hline 12 & CIS(D)/T & & 18373 & & 22 \\
\hline 13 & $\mathrm{CIS}(\mathrm{D}) / \mathrm{S}$ & & 18922 & & 55 \\
\hline 14 & CIS(D)/T & & 18835 & & 22 \\
\hline
\end{tabular}

Table 13. Excited state spectroscopic properties, Pentaaquauranyl in vacuum.

\begin{tabular}{|c|c|c|c|c|c|}
\hline & $\begin{array}{c}\text { mod } \\
\text { el }\end{array}$ & $\begin{array}{c}\text { method } \\
\text { basis }\end{array}$ & $\begin{array}{c}\omega_{\text {es,sym }} \\
{\left[\mathrm{cm}^{-1}\right]}\end{array}$ & $\begin{array}{c}\Delta \mathrm{R} \\
{[\mathrm{pm}]}\end{array}$ & $\begin{array}{c}\alpha_{\text {es }} \\
{\left[{ }^{\circ}\right]}\end{array}$ \\
\hline 1 & 55 & B3LYP/S & 833.1 & 4.58 & 180 \\
\hline 2 & 22 & & 834.5 & 4.63 & 176 \\
\hline 3 & 55 & B3LYP/T & & 4.88 & 180 \\
\hline 4 & 22 & & & 4.67 & 176 \\
\hline 5 & 55 & $\mathrm{CIS}-\mathrm{HF} / \mathrm{S}$ & 994.3 & 2.62 & 180 \\
\hline 6 & 22 & & 997.3 & 2.62 & 178 \\
\hline 7 & 22 & $\mathrm{CIS}-\mathrm{HF} / \mathrm{T}$ & & 2.77 & 178 \\
\hline
\end{tabular}

Table 14. Excited state spectroscopic properties, hydrated Pentaaquauranyl $\left[\mathrm{UO}_{2}\left(\mathrm{H}_{2} \mathrm{O}\right)_{5}\right]^{2+}$. $n \mathrm{H}_{2} \mathrm{O}$.

\begin{tabular}{|c|c|c|c|c|c|c|}
\hline & $\mathrm{n}$ & $\begin{array}{c}\text { method } \\
\text { basis }\end{array}$ & $\begin{array}{c}\omega_{\mathrm{es}, \mathrm{sym}} \\
{\left[\mathrm{cm}^{-1}\right]}\end{array}$ & $\begin{array}{c}\Delta \mathrm{R} \\
{[\mathrm{pm}]}\end{array}$ & $\begin{array}{c}\alpha_{\mathrm{es}} \\
{\left[{ }^{\circ}\right]}\end{array}$ & $\begin{array}{c}\mathrm{T}_{0,0} \\
{\left[\mathrm{~cm}^{-1}\right]}\end{array}$ \\
\hline 1 & 10 & $\mathrm{~B}$ LYP/S & 771.8 & 4.70 & 178 & 19966 \\
\hline 2 & 10 & $\mathrm{CIS} / \mathrm{S}$ & 960.4 & 2.52 & 179 & 24819 \\
\hline 3 & 10 & $\mathrm{~B} 3 \mathrm{LYP} / \mathrm{S}$ & 840.1 & 4.51 & 180 & 20181 \\
\hline $\mathbf{4}$ & 10 & $\mathrm{~B} 3 \mathrm{LYP} / \mathrm{T}$ & & 4.48 & 180 & \\
\hline 7 & 12 & $\mathrm{~B} 3 \mathrm{LYP} / \mathrm{S}$ & 803.3 & 4.60 & 177 & 20264 \\
\hline 8 & 12 & $\mathrm{~B} 3 \mathrm{LYP} / \mathrm{T}$ & 808.1 & 4.60 & 177 & \\
\hline 9 & 20 & $\mathrm{~B} 3 \mathrm{LYP} / \mathrm{S}^{-\mathrm{D}}$ & 802.8 & 4.64 & 179 & 19789 \\
\hline
\end{tabular}

Table 15. Excitation energies, hydrated Pentaaquauranyl $\left[\mathrm{UO}_{2}\left(\mathrm{H}_{2} \mathrm{O}\right)_{5}\right]^{2+} . n \mathrm{H}_{2} \mathrm{O}$.

\begin{tabular}{|c|c|c|c|c|c|}
\hline & $\mathrm{n}$ & $\begin{array}{c}\text { method } \\
\text { basis }\end{array}$ & $\begin{array}{c}\mathrm{T}_{\mathrm{e}} \\
{\left[\mathrm{cm}^{-1}\right]}\end{array}$ & $\begin{array}{c}\mathrm{T}_{\mathrm{de}} \\
{\left[\mathrm{cm}^{-1}\right]}\end{array}$ & $\begin{array}{c}\mathrm{T}_{\mathrm{a}} \\
{\left[\mathrm{cm}^{-1}\right]}\end{array}$ \\
\hline 1 & 10 & B3LYP/S-D & 20969 & 19382 & 20217 \\
\hline 2 & 10 & CIS/S & 25322 & 24605 & 24986 \\
\hline 3 & 10 & B3LYP/S & 21119 & 19617 & 20431 \\
\hline 4 & 10 & B3LYP/T & 20964 & 19411 & 20224 \\
\hline 5 & 10 & B3LYP/S & 21130 & 19585 & 20408 \\
\hline 6 & 10 & B3LYP/S & & 19311 & 20147 \\
\hline 7 & 12 & B3LYP/S & 21081 & 19520 & 20348 \\
\hline
\end{tabular}

${ }^{\mathrm{pp}}$ For CIS(D), the ground state was calculated by RI-MP2 method.

\begin{tabular}{|l|l|c|c|c|c|}
\hline 8 & 12 & B3LYP/T & 20846 & 19309 & 20116 \\
\hline 9 & 20 & B3LYP/S $^{-D}$ & 20792 & 19032 & 19956 \\
\hline
\end{tabular}

\subsection{Uranyl Monosulfate, $\mathrm{UO}_{2} \mathrm{SO}_{4}$}

Uranyl Monosulfate complex, $\mathrm{UO}_{2} \mathrm{SO}_{4}$, as mentioned in 2.3 section has several isomeric forms differing by the uranyl group coordination number (5 or 6, Fig. 21) and dentacity of coordinated sulfate ligand (1 (Fig. 22) or 2 (Fig. 21)).

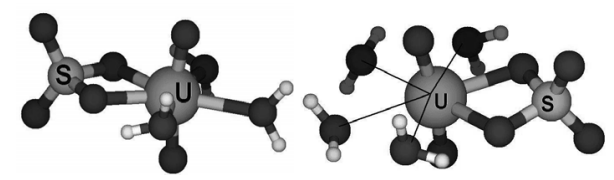

Fig. 21: $\left[\mathrm{UO}_{2}\left(\kappa^{2}-\mathrm{SO}_{4}\right)\left(\mathrm{H}_{2} \mathrm{O}\right)_{3}\right]\left(\kappa^{2} \mathrm{co} 5\right.$, left $)$ and $\left[\mathrm{UO}_{2}\left(\kappa^{2}-\right.\right.$ $\left.\left.\mathrm{SO}_{4}\right)\left(\mathrm{H}_{2} \mathrm{O}\right)_{4}\right]\left(\kappa^{2} \mathrm{co} 6\right.$, right $)$ ground state equilibrium geometries by DFT/B3-LYP/defTZVPP method

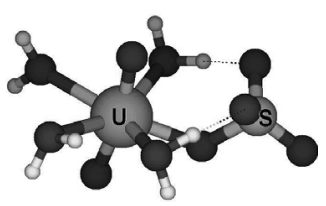

Fig. 22: $\left[\mathrm{UO}_{2}\left(\kappa^{1}-\mathrm{SO}_{4}\right)\left(\mathrm{H}_{2} \mathrm{O}\right)_{4}\right]\left(\kappa^{1} \mathrm{co} 5\right)$ ground state equilibrium geometry by DFT/B3-LYP/defSVP method

For the fourth possibility, $\left[\mathrm{UO}_{2}\left(\kappa^{1}-\mathrm{SO}_{4}\right)\left(\mathrm{H}_{2} \mathrm{O}\right)_{5}\right]$ $\left(\kappa^{1} \mathrm{co6}\right)$ no energy minimum has been found up to now. All geometry optimizations led either to water molecule drive out from the coordination plane or to hydrogen transfer from coordinated water molecule to sulphate ligand creating more stable $\left[\mathrm{UO}_{2}\left(\kappa^{1}-\mathrm{HSO}_{4}\right)(\mathrm{OH})\left(\mathrm{H}_{2} \mathrm{O}\right)_{4}\right]$. Ground state properties in vacuum are summarized in Table $16, \kappa^{2} \operatorname{co} 5 \mathrm{~h}$ and $\kappa^{1} \mathrm{co} 5 \mathrm{~h}$ in first column stands for $\left[\mathrm{UO}_{2}\left(\kappa^{2}-\mathrm{SO}_{4}\right)\left(\mathrm{H}_{2} \mathrm{O}\right)_{3}\right] \cdot \mathrm{H}_{2} \mathrm{O}$ and $\left[\mathrm{UO}_{2}\left(\kappa^{1}-\mathrm{SO}_{4}\right)\left(\mathrm{H}_{2} \mathrm{O}\right)_{4}\right] \cdot$ $\mathrm{H}_{2} \mathrm{O}$ respectively.

Table 16. Uranyl Monosulphate in vacuum, ground state properties. $E_{r e f}=-1555,953902886 \mathrm{H}$ (hartree) for the first four rows (the $\kappa^{2} \operatorname{co} 5$ isomer), $E_{r e f}=-1632,415734279 \mathrm{H}$ for others.

\begin{tabular}{|c|c|c|c|c|c|c|}
\hline isomer & $\begin{array}{c}\text { method } \\
\text { basis }\end{array}$ & $\begin{array}{l}\omega_{\text {sym }, 1} \\
{\left[\mathrm{~cm}^{-1}\right]}\end{array}$ & $\begin{array}{l}\omega_{\text {sym }, 2} \\
{\left[\mathrm{~cm}^{-1}\right]}\end{array}$ & $\begin{array}{c}R_{\min } \\
{[\mathrm{pm}]}\end{array}$ & $\begin{array}{c}\alpha \\
{\left[{ }^{\circ}\right]}\end{array}$ & $\begin{array}{c}E-E_{\text {ref }} \\
{[\mathrm{H}]}\end{array}$ \\
\hline$\kappa^{2} \cos$ & DFT/S & 841.7 & 886.0 & 177.8 & 168 & 1.0036 \\
\hline$\kappa^{2} \cos$ & DFT/T & 851.2 & 881.2 & 177.5 & 167 & 0.0000 \\
\hline$\kappa^{2} \cos$ & $\mathrm{SCF} / \mathrm{S}$ & 1005 & 1057 & 171.3 & 171 & 6.4363 \\
\hline$\kappa^{2} \operatorname{co5}$ & $\mathrm{SCF} / \mathrm{T}$ & 1024 & 1059 & 170.8 & 171 & 5.4066 \\
\hline$\kappa^{2} \operatorname{co6}$ & DFT/S & 861.0 & 889.4 & 177.6 & 171 & 1.1099 \\
\hline$\kappa^{2} \operatorname{co6} 6$ & DFT/S & 859.3 & 890.0 & 177.6 & 171 & 1.1112 \\
\hline$\kappa^{2} \cosh$ & DFT/S & 849.3 & 884.0 & 177.9 & 169 & 1.0986 \\
\hline$\kappa^{2} \cosh$ & DFT/T & 858.7 & 883.6 & 177.4 & 169 & 0.0000 \\
\hline$\kappa^{2} \operatorname{co} 6$ & DFT/T & 868.0 & 890.0 & 177.1 & 170 & 0.0125 \\
\hline$\kappa^{2} \operatorname{co6}$ & $\mathrm{SCF} / \mathrm{S}$ & 1024 & 1061 & 171.0 & 174 & 6.9158 \\
\hline$\kappa^{1} \cosh$ & DFT/S & 892.6 & & 177.5 & 173 & \\
\hline$\kappa^{1} \cos$ & DFT/S & 886.7 & & 177.7 & 167 & 1.1133 \\
\hline
\end{tabular}

The water molecule drives out from the coordination plane can be exploited for preliminary energy comparison between $\kappa^{2} \operatorname{co} 6$ and $\kappa^{2} \cos$ isomers (at the DFT/B3LYP/defTZVPP level, $\kappa^{2} \operatorname{co} 5$ is favoured by 12.5 
$\mathrm{mH}=2736 \mathrm{~cm}^{-1}=32.7 \mathrm{~kJ} / \mathrm{mol}$, inclusion of $\mathrm{ZPE}$ difference, $33.8 \mathrm{~kJ} / \mathrm{mol}$ ). The standard reaction gibbs function change $\Delta \mathrm{G}^{\circ}$ for the chemical reaction

$$
\begin{array}{r}
{\left[\mathrm{UO}_{2}\left(\kappa^{2}-\mathrm{SO}_{4}\right)\left(\mathrm{H}_{2} \mathrm{O}\right)_{3}\right] \cdot \mathrm{H}_{2} \mathrm{O}} \\
{\left[\mathrm{UO}_{2}\left(\kappa^{2}-\mathrm{SO}_{4}\right)\left(\mathrm{H}_{2} \mathrm{O}\right)_{4}\right]}
\end{array}
$$

can be estimated as $\Delta G^{\circ}=31.6 \mathrm{~kJ} / \mathrm{mol}$, corresponding to $K^{\circ}=2.9 \cdot 10^{-6}$ for standard temperature $T=298.15 \mathrm{~K}$ (i.e. the $\kappa^{2} \operatorname{co} 5$ is significantly preferred over $\kappa^{2} \operatorname{co} 6$ in vacuum). Similarly, for the reaction

$$
\left[\mathrm{UO}_{2}\left(\kappa^{2}-\mathrm{SO}_{4}\right)\left(\mathrm{H}_{2} \mathrm{O}\right)_{4}\right] \quad\left[\mathrm{UO}_{2}\left(\kappa^{1}-\mathrm{SO}_{4}\right)\left(\mathrm{H}_{2} \mathrm{O}\right)_{4}\right]
$$

$\Delta G^{\circ}=13.8 \mathrm{~kJ} / \mathrm{mol}$ and $K^{\circ}=3.85 \cdot 10^{-3}(T=298.15 \mathrm{~K})$ (i.e. the $\kappa^{1}$ - isomer is present in less than $0.4 \%$ in equilibrium within this level of theory). DFT functional in the Table 16 was B3LYP.

The coordination of sulphate ligand led to uranyl group symmetric vibrational mode coupling with the ligand vibrational modes. The result are two modes separated by $33_{-11}^{+22} \mathrm{~cm}^{-1}$ (the sub/superscript corresponds to extremal deviations) in average. The red-shifted part of the pair corresponds to the synchronous move of z-axis (uranyl group) projections of uranyl oxygen atoms and non-donor oxygen atoms of the sulphate and is denoted as $\omega_{\text {sym }, 1}$ in Table 16. The blue-shifted part corresponds to the anti-synchronous change of the $\mathrm{z}$-coordinate $\left(\omega_{\mathrm{sym}, 2}\right.$ in Tab. 16). This effect has been smaller for the excited electronic state and only one frequency is listed in the respective table of excited state properties (Table 18).

Table 17: Excited state spectroscopic properties, Uranyl Monosulphate in vacuum.

\begin{tabular}{|c|c|c|c|c|c|}
\hline isomer & $\begin{array}{c}\text { method } \\
\text { basis }\end{array}$ & $\begin{array}{c}\mathrm{T}_{\mathrm{e}} \\
{\left[\mathrm{cm}^{-1}\right]}\end{array}$ & isomer & $\begin{array}{c}\text { method } \\
\text { basis }\end{array}$ & $\begin{array}{c}\mathrm{T}_{\mathrm{e}} \\
{\left[\mathrm{cm}^{-1}\right]}\end{array}$ \\
\hline$\kappa^{2} \operatorname{co5}$ & B3LYP/S & 17640 & $\kappa^{2} \operatorname{co} 6$ & B3LYP/S & 18231 \\
\hline$\kappa^{2} \operatorname{co5} 5$ & B3LYP/T & 17412 & $\kappa^{2} \operatorname{co5h}$ & B3LYP/S & 18418 \\
\hline$\kappa^{2} \operatorname{co5}$ & CIS-HF/S & 24537 & $\kappa^{2} \operatorname{co} 6$ & CIS-HF/S & 24477 \\
\hline$\kappa^{2} \operatorname{co5} 5$ & CIS-HF/T & 24349 & $\kappa^{1} \operatorname{co5h}$ & B3LYP/S & 18866 \\
\hline$\kappa^{2} \operatorname{co} 6$ & B3LYP/S & 18011 & & & \\
\hline
\end{tabular}

Table 18. Excited state spectroscopic properties, Uranyl Monosulphate in vacuum. The method is CIS-HF for all three calculations, basis is denoted "b." in the second column.

\begin{tabular}{|c|c|c|c|c|c|c}
\hline isomer & b. & $\begin{array}{c}\omega_{\text {es,sym }} \\
{\left[\mathrm{cm}^{-1}\right]}\end{array}$ & $\begin{array}{c}\Delta \mathrm{R} \\
{[\mathrm{pm}]}\end{array}$ & $\begin{array}{c}\alpha_{\mathrm{es}} \\
{\left[{ }^{\circ}\right]}\end{array}$ & $\begin{array}{c}\mathrm{T}_{\mathrm{v}, \mathrm{d}} \\
{\left[\mathrm{cm}^{-1}\right]}\end{array}$ & $\begin{array}{c}\mathrm{T}_{00} \\
{\left[\mathrm{~cm}^{-1}\right]}\end{array}$ \\
\hline$\kappa^{2} \operatorname{co5}$ & $\mathrm{S}$ & 942.7 & 2.39 & 171 & 23931 & 24064 \\
\hline$\kappa^{2} \operatorname{co5} 5$ & $\mathrm{~T}$ & & 2.53 & 170 & 23671 & \\
\hline$\kappa^{2} \operatorname{co} 6$ & $\mathrm{~S}$ & 944.5 & 2.46 & 173 & 23838 & 23963 \\
\hline
\end{tabular}

Properties of the lowest triplet state are summarized in Tables 17 and 18. The basis set change from defSVP ("S") to defTZVPP ("T") led to decrease of $1.03 \mathrm{H}$ in $\kappa^{2} \cos$ excited state energy (PES minima both) resulting in

${ }^{\mathrm{qq}}$ Furthermore, for $n=55$ solvating water molecules models here, only the coordinates of solute atoms have been varied within the DFT energy optimization. The solvent atomic coordinates have been optimized only change of the adiabatic excitation energy $T_{a}$ from 24248 $\mathrm{cm}^{-1}$ to $24024 \mathrm{~cm}^{-1}$

The two fragment BSSE correction was computed for the single point in the DFT/B3-LYP equilibrium geometries for the $\kappa^{2} \operatorname{co} 5$ isomer. The sulphate ligand with charge -2 was considered as one of the fragments. The resulting corrections were $60.87 \mathrm{mH}$ (defSVP) and 12.15 $\mathrm{mH}$ (defTZVPP).

The hydration effect will be shown for $\kappa^{2} \cos$ isomer here only (it is the most stable isomer in vacuum, however, the hydration can change the isomeric relative stabilities significantly). The other isomers hydration will be discussed in the Supplementary Information. We have used the RI-DFT method for the 55 solvent water structures to reduce the computational demands ${ }^{\mathrm{qq}}$, but are aware that the compatible GGA functional B-P underestimates vibrational frequencies (which are still to be assigned to the corresponding modes) and is in general less accurate than the hybrid B3-LYP functional. The small energy differences for $n=10$ (Tab. 19, first three rows) are rather results of similar input geometries for the geometry optimization. More elaborate study, where configuration space will be rigorously searched by MD should be done. The respective equilibrium geometries are shown in Fig. 23-25.

Table 19. Hydrated $\left[\mathrm{UO}_{2}\left(\kappa^{2}-\mathrm{SO}_{4}\right)\left(\mathrm{H}_{2} \mathrm{O}\right)_{3}\right] \cdot n \mathrm{H}_{2} \mathrm{O}$, ground state properties and vertical excitation energy $\mathrm{T}_{\mathrm{e}}(n=10$ : DFT/B3LYP/defSVP method, $n=55$ : RI-DFT/B-P/defSVP method)

\begin{tabular}{|c|c|c|c|c|c|c|}
\hline$n$ & $\begin{array}{c}\omega_{\text {sym } 1} \\
{\left[\mathrm{~cm}^{-1}\right]}\end{array}$ & $\begin{array}{c}\omega_{\text {sym }, 2} \\
{\left[\mathrm{~cm}^{-1}\right]}\end{array}$ & $\begin{array}{c}\mathrm{R}_{\min } \\
{[\mathrm{pm}]}\end{array}$ & $\begin{array}{c}\alpha \\
{\left[{ }^{\circ}\right]}\end{array}$ & $\begin{array}{c}\mathrm{T}_{\mathrm{e}} \\
{\left[\mathrm{cm}^{-1}\right]}\end{array}$ & $\begin{array}{c}\text { E-E } \\
{[\mathrm{mH}]}\end{array}$ \\
\hline 10 & 904.7 & 914.0 & 176.6 & 176 & 20406 & 0.00 \\
\hline 10 & 842.8 & 855.0 & 179.0 & 174 & 20282 & 6.21 \\
\hline 10 & 862.5 & 881.7 & 177.9 & 178 & 20327 & 4.30 \\
\hline 55 & & & 177.8 & 168 & & 0.00 \\
\hline 55 & & & 179.2 & 167 & & 423.00 \\
\hline
\end{tabular}

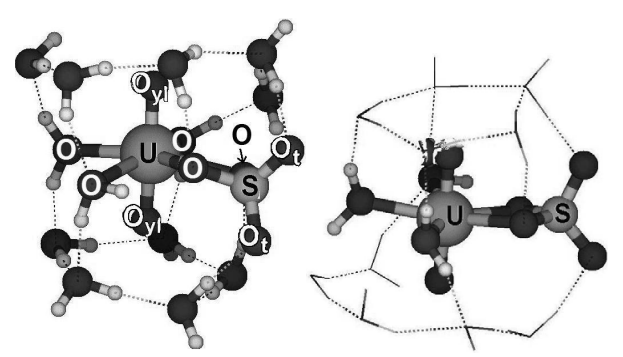

Fig. 23. Equilibrium geometries computed by DFT/B3LYP/defSVP method for $\left[\mathrm{UO}_{2}\left(\kappa^{2}-\mathrm{SO}_{4}\right)\left(\mathrm{H}_{2} \mathrm{O}\right)_{3}\right] \cdot 10 \mathrm{H}_{2} \mathrm{O}$ model. The left side corresponds to first, the right side to third row in Table 19. once prior the DFT calculation by universal force-field calculation (the Turbomole default UFF [103], first row under thick line in Table 19) or used from the Packing program [102]. 


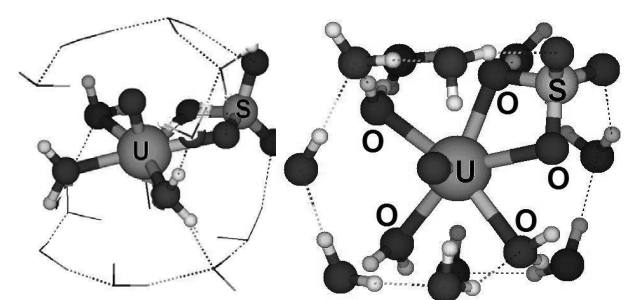

Fig. 24. Equilibrium geometry computed by DFT/B3LYP/defSVP method for $\left[\mathrm{UO}_{2}\left(\kappa^{2}-\mathrm{SO}_{4}\right)\left(\mathrm{H}_{2} \mathrm{O}\right)_{3}\right] \cdot 10 n \mathrm{H}_{2} \mathrm{O}$ model (second row in Tab. 19). The right side is a top view on the molecule on left side, donor oxygens are labeled for clarity.

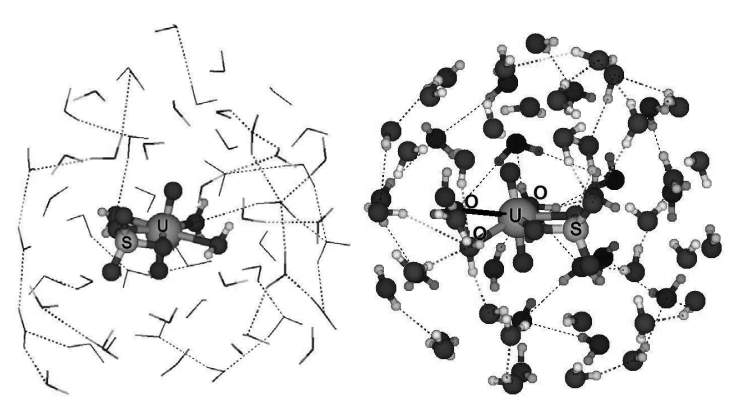

Fig. 25. Equilibrium geometries computed by RI-DFT/B$\mathrm{PB} 3 \mathrm{LYP} /$ defSVP method for $\left[\mathrm{UO}_{2}\left(\kappa^{2}-\mathrm{SO}_{4}\right)\left(\mathrm{H}_{2} \mathrm{O}\right)_{3}\right] \cdot 55 \mathrm{H}_{2} \mathrm{O}$ model. The left side corresponds to first, the right side to second respective row (under the thick line) in Table 19.

From a batch of 8 possible initial geometries based on idea of "sandwich" structure, where the equatorial coordination plane of the complex is the "filler" and two pentagonal ring of water molecules (connected by $\mathrm{H}-$ bonds to each other and to donor oxygen atoms of the complex) are "bread" (the initial geometries different by whether the rings have the asymmetric H-bonds oriented in the same or in the opposite directions, by dihedral angles, etc.) several local PES minima were found (the three lowest are presented in Table 19).

In order to investigate possible mechanisms of peak broadening, we have used a luminescence peak model

$$
V(v)=\sum_{k=1}^{8} B\left(v_{\max , k}, T\right) \cdot \exp \left(-\frac{\left(v-v_{\max , k}\right)^{2}}{2 \sigma^{2}}\right)
$$

where $v$ is wave-number, $v_{\max , k}$ corresponds to the vertical excitation energy (the spread of vertical excitation energies $T_{e}$ with the respect to different solvation surroundings should be similar to the spread of $T_{00}$ values) of the $k$-th local PES minima discussed in previous paragraph, $\sigma$ is an empirical width-parameter $\left(\mathrm{s}=60 \mathrm{~cm}^{-1}\right.$ was used here) and $T$ is thermodynamic temperature (for demonstrability we used triple of the standard temperature here),

$$
B\left(v_{\max , k}, T\right)=\frac{1}{Z} \exp \left(-\frac{h v_{\max , k}}{k_{B} T}\right),
$$

is a Boltzmann factor, $Z$ is partial sum,

$$
Z=\sum_{k=1}^{8} \exp \left(-\frac{h v_{\max , k}}{k_{B} T}\right)
$$

$h, k_{B}$ are Planck and Boltzmann constants. The Figure 26 shows that resulting peak FWHM is around $180 \mathrm{~cm}^{-1}$ (the total spread of $T_{e}$ (highlighted by dashed vertical lines in Fig. 26) within over batch of initial geometries is $680 \mathrm{~cm}^{-}$ ${ }^{1}$ ). The experimental luminescence 0 ' $\rightarrow 0$ peak FWHM is around $700 \mathrm{~cm}^{-1}$. The discrepancy is a result of very simplified model of one kind of peak broadening only.

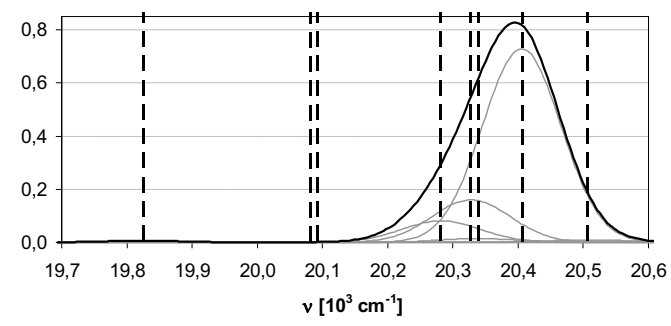

Fig. 26. Peak modelled according to eq. (63) for luminescence peak-width explanatory discussion.

\subsection{Uranyl bis(sulfate), $\mathrm{UO}_{2}\left(\mathrm{SO}_{4}\right)_{2}{ }^{2-}$}

We briefly present vacuum results for $\mathrm{UO}_{2}\left(\mathrm{SO}_{4}\right)_{2}{ }^{2-}$ in Tab. 20, the method DFT-D3/B3-LYP was used, basis is denoted "b.", $\omega_{\text {sym }}$ in $\mathrm{cm}^{-1}$ stands for simple average over all modes where symmetric stretching of uranyl group was significant. For the corresponding equilibrium geometries, see Fig. 27.

For $\kappa^{22} \cos$ and $\kappa^{12} \operatorname{co} 5$ isomers, TDDFT/B3-LYP excited state geometry optimization led to $T_{0-0}, \omega_{e s, s y m}, \Delta R$ and $\alpha_{e s}$ values in Tab. 21.

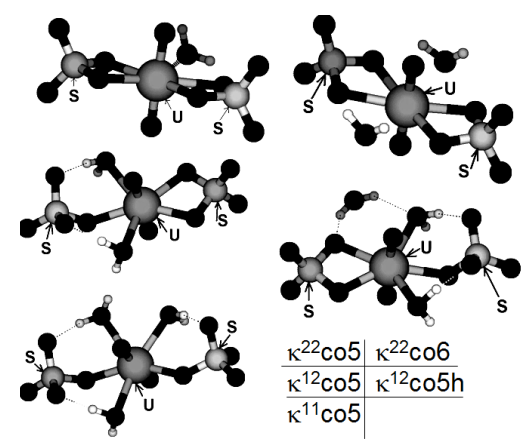

Fig. 27. Equilibrium geometries for several uranyl bis(sulphate) isomers, DFT-D3/B3LYP/def-TZVPP method.

Table 20. Uranyl Bis(sulphate) $\left(\mathrm{UO}_{2}\left(\mathrm{SO}_{4}\right)_{2}{ }^{2-}\right)$ in vacuum, ground state properties and vertical excitation energies. $E_{r e f, 1}=$ $2102,2549546 \mathrm{H}$ for the first two rows (the $\kappa^{22} \operatorname{co} 5$ isomer $\left.\left[\mathrm{UO}_{2}\left(\mathrm{SO}_{4}\right)_{2}\left(\mathrm{H}_{2} \mathrm{O}\right)\right]^{2-}\right), E_{r e f, 2}=-2178,7093575 \mathrm{H}$ for $\kappa^{12} \operatorname{co} 5$ and $\kappa^{22} \mathrm{co} 6$ isomers $\left[\mathrm{UO}_{2}\left(\mathrm{SO}_{4}\right)_{2}\left(\mathrm{H}_{2} \mathrm{O}\right)_{2}\right]^{2-}$ and $E_{r e f, 3}=-2255,1593788$ $\mathrm{H}$ for $\kappa^{11} \operatorname{co} 5 \quad\left(\left[\mathrm{UO}_{2}\left(\mathrm{SO}_{4}\right)_{2}\left(\mathrm{H}_{2} \mathrm{O}\right)_{3}\right]^{2-}\right)$ and $\kappa^{12} \operatorname{co} 5 \mathrm{~h}$ $\left(\left[\mathrm{UO}_{2}\left(\mathrm{SO}_{4}\right)_{2}\left(\mathrm{H}_{2} \mathrm{O}\right)_{2}\right]^{2-} . \mathrm{H}_{2} \mathrm{O}\right)$. Uranyl Tris(sulphate) in vacuum (last two rows, $E_{\text {ref }}=-2724,5375210 \mathrm{H}$ )

\begin{tabular}{|c|c|c|c|c|c|c|}
\hline isomer & b. & $\begin{array}{c}\omega_{\text {sym }} \\
{\left[\mathrm{cm}^{-}\right.} \\
\left.{ }^{1}\right]\end{array}$ & $\begin{array}{c}\mathrm{T}_{\mathrm{e}} \\
{\left[\mathrm{cm}^{-1}\right]}\end{array}$ & $\begin{array}{c}\mathrm{R}_{\min } \\
{[\mathrm{pm}]}\end{array}$ & $\begin{array}{c}\alpha \\
{\left[{ }^{\circ}\right]}\end{array}$ & $\begin{array}{c}\text { E-E } \\
{[\mathrm{H}]}\end{array}$ \\
\hline $\mathrm{\kappa}^{22} \operatorname{co5}$ & $\mathrm{S}$ & 859 & 19468 & 179.0 & 176 & 1.3732 \\
\hline
\end{tabular}




\begin{tabular}{|c|c|c|c|c|c|c|}
\hline $\boldsymbol{\kappa}^{22} \mathbf{c o 5}$ & $\mathbf{T}$ & $\mathbf{8 8 0}$ & $\mathbf{1 9 3 4 1}$ & $\mathbf{1 7 8 . 4}$ & $\mathbf{1 7 6}$ & $\mathbf{0 . 0 0 0 0}$ \\
\hline$\kappa^{12} \operatorname{co} 5$ & $\mathrm{~S}$ & 865 & 19762 & 178.2 & 177 & 1.4678 \\
\hline $\boldsymbol{\kappa}^{12} \operatorname{co5}$ & $\mathrm{T}$ & $\mathbf{8 4 7}$ & $\mathbf{1 9 7 6 2}$ & $\mathbf{1 7 7 . 8}$ & $\mathbf{1 7 7}$ & $\mathbf{0 . 0 0 0 0}$ \\
\hline$\kappa^{11} \operatorname{co5} 5$ & $\mathrm{~S}$ & 839 & 19622 & 178.4 & 177 & 1.5663 \\
\hline $\boldsymbol{\kappa}^{11} \operatorname{co5}$ & $\mathrm{T}$ & $\mathbf{8 5 3}$ & $\mathbf{1 9 3 3 6}$ & $\mathbf{1 7 7 . 8}$ & $\mathbf{1 7 7}$ & $\mathbf{0 . 0 0 0 0}$ \\
\hline$\kappa^{22} \operatorname{co} 6$ & $\mathrm{~S}$ & 872 & 19942 & 178.7 & 179 & 1.4756 \\
\hline $\boldsymbol{\kappa}^{22} \operatorname{co6}$ & $\mathbf{T}$ & $\mathbf{8 7 7}$ & $\mathbf{1 9 7 9 2}$ & $\mathbf{1 7 8 . 1}$ & $\mathbf{1 7 9}$ & $\mathbf{0 . 0 0 4 4}$ \\
\hline$\kappa^{12} \cosh$ & $\mathrm{S}$ & 872 & 19410 & 178.5 & 178 & 1.5678 \\
\hline Trissulf & $\mathrm{S}$ & 834 & 20646 & 179.1 & 180 & 1.8642 \\
\hline Trissulf & $\mathbf{T}$ & $\mathbf{8 3 6}$ & $\mathbf{2 0 4 6 8}$ & $\mathbf{1 7 8 . 3}$ & $\mathbf{1 8 0}$ & $\mathbf{0 . 0 0 0 0}$ \\
\hline
\end{tabular}

Table 21: Excited state spectroscopic properties, Uranyl $\mathrm{Bis}$ (sulfate) $\left(\mathrm{UO}_{2}\left(\mathrm{SO}_{4}\right)_{2}{ }^{2-}\right)$ in vacuum.

\begin{tabular}{|c|c|c|c|c|c|}
\hline isomer & b. & $\begin{array}{c}\omega_{\text {es,sym }} \\
{\left[\mathrm{cm}^{-1}\right]}\end{array}$ & $\begin{array}{c}\Delta \mathrm{R} \\
{[\mathrm{pm}]}\end{array}$ & $\begin{array}{c}\alpha_{\mathrm{es}} \\
{\left[{ }^{\circ}\right]}\end{array}$ & $\begin{array}{c}\mathrm{T}_{0,0} \\
{\left[\mathrm{~cm}^{-1}\right]}\end{array}$ \\
\hline $\mathrm{\kappa}^{22} \operatorname{co5} 5$ & $\mathrm{~S}$ & 762.7 & 3.62 & 175 & 18749 \\
\hline $\mathrm{\kappa}^{22} \operatorname{co} 5$ & $\mathrm{~T}$ & & 3.66 & 175 & \\
\hline $\mathrm{\kappa}^{12} \operatorname{co5}$ & $\mathrm{S}$ & 820.2 & 1.44 & 176 & 13082 \\
\hline
\end{tabular}

\subsection{Uranyl tris(sulphate), $\mathrm{UO}_{2}\left(\mathrm{SO}_{4}\right)_{3}{ }^{4-}$}

For uranyl tris(sulphate), $\left[\mathrm{UO}_{2}\left(\kappa^{2}-\mathrm{SO}_{4}\right)_{3}\right]^{4-}$, inclusion of one incomplete ( 30 water molecules) hydration sphere on vibrational frequency wsym (increased by $45 \mathrm{~cm}^{-1}$ ) and vertical excitation energy $\left(T_{e}\right.$, decreased by $418 \mathrm{~cm}^{-1}$, Tab. 20 - last two rows, Tab. 22 - first row). Equilibrium geometry for the lowest local PES minimum yet found is depcited in Fig. 27.

Table 22: $\left[\mathrm{UO}_{2}\left(\kappa^{2}-\mathrm{SO}_{4}\right)_{3}\right]^{4-} \cdot 30 \mathrm{H}_{2} \mathrm{O}\left(E_{\text {ref }}=-5013,7054062 \mathrm{H}\right)$, $R_{\text {min }}=177.1 \mathrm{pm}$ and $\alpha=180^{\circ}$ for all lines below.

\begin{tabular}{|r|r|r|r|}
\hline \multicolumn{1}{|r|}{ ref. } & $\begin{array}{c}\omega_{\text {sym }} \\
{\left[\mathrm{cm}^{-1}\right]}\end{array}$ & $\begin{array}{c}\mathrm{T}_{\mathrm{e}} \\
{\left[\mathrm{cm}^{-1}\right]}\end{array}$ & $\begin{array}{c}\text { E-E } \\
{[\mathrm{mH}]}\end{array}$ \\
\hline 1 & 879.2 & 20228 & 0 \\
\hline 2 & 878.0 & 20233 & 0.41 \\
\hline 3 & 879.2 & 20225 & 0.77 \\
\hline 4 & 879.4 & 20221 & 0.81 \\
\hline 5 & 876.7 & 20233 & 1.18 \\
\hline 6 & 878.8 & 20231 & 1.20 \\
\hline 7 & 884.2 & 20224 & 1.29 \\
\hline 8 & 880.5 & 20514 & 8.13 \\
\hline
\end{tabular}

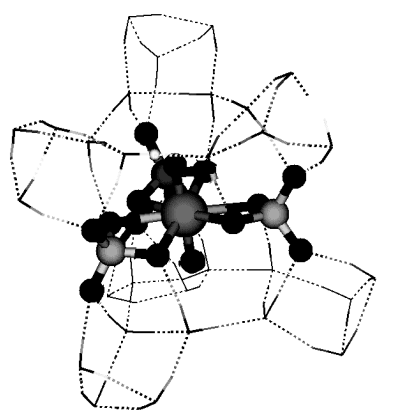

Fig. 27: $\left[\mathrm{UO}_{2}\left(\kappa^{2}-\mathrm{SO}_{4}\right)_{3}\right]^{4-} \cdot 30 \mathrm{H}_{2} \mathrm{O}$ equilibrium geometry, DFTD3/B3LYP/def-SVP method.

\subsection{Uranyl mono(selenate), $\mathrm{UO}_{2} \mathrm{SeO}_{4}$}

Table 23. Uranyl Monoselenate $\left(\mathrm{UO}_{2} \mathrm{SeO}_{4}\right)$ in vacuum. ground state properties. $E_{\text {ref }}=-1555.953902886 \mathrm{H}$ (hartree) for the first

\footnotetext{
${ }^{\mathrm{rr}}$ FWHM not included in the uncertainity.
}

four rows (the $\kappa^{2} \cos$ isomer). $E_{r e f}=-1632.415734279 \mathrm{H}$ for others.

\begin{tabular}{|c|c|r|r|r|c|c|}
\hline isomer & b. & $\begin{array}{c}\omega_{\text {sym }} \\
{\left[\mathrm{cm}^{-1}\right]}\end{array}$ & $\begin{array}{c}\mathrm{T}_{\mathrm{e}} \\
{\left[\mathrm{cm}^{-1}\right]}\end{array}$ & $\begin{array}{c}\mathrm{R}_{\min } \\
{[\mathrm{pm}]}\end{array}$ & $\begin{array}{c}\alpha \\
{\left[{ }^{\circ}\right]}\end{array}$ & $\begin{array}{c}\text { E-E } \\
{[\mathrm{H}]}\end{array}$ \\
\hline$\kappa^{2} \operatorname{co5} 5$ & $\mathrm{~S}$ & 883 & 18406 & 177.8 & 168 & 1.1505 \\
\hline $\boldsymbol{\kappa}^{2} \mathbf{c o 5}$ & $\mathbf{T}$ & 877 & 18250 & 177.4 & 167 & 0.0000 \\
\hline $\boldsymbol{\kappa}^{2} \operatorname{co5h}$ & $\mathrm{S}$ & 880 & 18772 & 177.9 & 170 & 1.2325 \\
\hline$\kappa^{2} \operatorname{co6}$ & $\mathrm{S}$ & 885 & 18720 & 177.5 & 170 & 1.2482 \\
\hline$\kappa^{1} \operatorname{co5}$ & $\mathrm{S}$ & 885 & 19409 & 177.7 & 167 & 1.2441 \\
\hline $\boldsymbol{\kappa}^{1} \mathbf{c o 5}$ & $\mathbf{T}$ & 882 & & 178.3 & 167 & 0.0000 \\
\hline
\end{tabular}

\subsection{Other complex molecules}

We greatly apologize to the reader, quantum chemical calculations of the 1:2 and 1:3 sulphates as well as selenates and carbonates will be introduced in the Supplementary Information and further performed in Višňák dissertation thesis.

\section{Conclusions}

For $\mathrm{UO}_{2}{ }^{2+}-\mathrm{SO}_{4}{ }^{2-}$ and $\mathrm{UO}_{2}{ }^{2+}-\mathrm{SeO}_{4}{ }^{2-}$ systems, good agreement between here presented experimental spectroscopic and thermodynamic properties and data of other authors has been found. The uranyl - selenate complex species are slightly less stable than the corresponding uranyl - sulphate species (Tab. 2, Tab. 3) since selenate is weaker Lewis base than sulphate while uranyl is strong Lewis acid $[9,36]$. The shapes of absorption spectra are identical for uranyl sulphates and selenates within measurement error, the luminescence spectral shapes are very close to each other as well. This can be demonstrated on similar spectroscopic properties $T_{0-0}$ and $\omega_{g s}$ (Tab. 5, Tab. 7 - however, please note the different ionic strengths).

For the reference, the $\left[\mathrm{UO}_{2}\left(\mathrm{H}_{2} \mathrm{O}\right)_{5}\right]^{2+} \quad 0 \rightarrow 0$ deexcitation energy has been experimentally determined as $T_{0-0}=(20490 \pm 30) \mathrm{cm}^{-1}$ (Tab. 5 and Tab. 7 average $^{\mathrm{rr}}$ ) and the effective uranyl symmetric stretching vibrational frequency (in ground electronic state) $\omega_{g s}=(873 \pm 13) \mathrm{cm}^{-1}$. The one ligand coordination leads to bathochromic shift ${ }^{\mathrm{ss}}$ of $140 \pm 30 \mathrm{~cm}^{-1}(0.7 \%)$ for the sulphate (Tab. 5) and of $180 \pm 30 \mathrm{~cm}^{-1}$ for the selenate. The two ligand coordination produce bathochromic shift 230 and $270 \mathrm{~cm}^{-1}$ for sulphate and selenate respectively. The vibrational frequency is decreased by $\approx 20 \mathrm{~cm}^{-1}$ by any coordination, however, this effect is within the measurement error. Yet only for hydrated uranyl luminescence spectrum, the $\Delta R$ parameter fit has been done, $\Delta R=(16 \pm 4) \mathrm{pm}$ (Fig. 6).

Quasi-relativistic,

DFT-D3/B3-LYP/def-SVP theoretical estimates of spectroscopic parameters have been done for complex species in vacuum and in aqueous solution (modelled by explicit solvation, yet, by small number of surrounding water molecules). For $\left[\mathrm{UO}_{2}\left(\mathrm{H}_{2} \mathrm{O}\right)_{5}\right]^{2+}$ the vacuum $T_{0-0}$ prediction is $19.8 \times 10^{3} \mathrm{~cm}^{-}$ ${ }^{1}$ (Tab. 12) and the $T_{0-0}$ vary between $(19.8-20.3) \times 10^{3} \mathrm{~cm}^{-1}$ (Tab. 14) for solvated model. The latter value is in good agreement with the experimental value, in particular, if we

${ }^{\text {ss }}$ The $T_{0-0}$ decrease. 
include the FWHM into experimental uncertainty. The $\left[\mathrm{UO}_{2}\left(\mathrm{H}_{2} \mathrm{O}\right)_{5}\right]^{2+}$ in vacuum vibrational frequency $\omega_{g s}$ has been predicted as $947 \mathrm{~cm}^{-1}$ by DFT/B3-LYP and as 888 $\mathrm{cm}^{-1}$ by MP2 (Tab. 9). Inclusion of 10, 12 and 20 solvation water molecules led to gradual wgs decrease to 927,911 and $894 \mathrm{~cm}^{-1}$ respectively (Tab. 10, see the energy lowest "B3LYP/T" model). The values for 55 water molecules are less reliable since approximative structure optimization has been used in that cases. The $\left[\mathrm{UO}_{2}\left(\mathrm{H}_{2} \mathrm{O}\right)_{5}\right]^{2+} .20 \mathrm{H}_{2} \mathrm{O} \omega_{g s}$ of $894 \mathrm{~cm}^{-1}$ seems to be very promisive in comparison with experimental data.

The theoretical predictions for $\Delta R$ are less than $5 \mathrm{pm}$, while experiment suggest more than $12 \mathrm{pm}$ (average 16 $\mathrm{pm})$. The discrepancy could be explained by simplicity of the one-mode-oscillator model for $\Delta R$ fit from the experimental data. In is likely, that more vibrational modes with similar (or similar to multiples) frequencies will resolve the luminescence spectra and the $16 \mathrm{pm}$ therefore corresponds to sum of equilibrium position shifts over all vibrational modes coupling to the luminescence transition. The more detailed Franck-Condon factors analysis should clarify this.

Facing technical problems, we were able to determine $T_{0-0}$ (within TDDFT/B3-LYP/def-SVP) only for uranyl bis (sulphate) $\kappa^{22} \mathrm{co} 5$ isomer in vacuum as $18749 \mathrm{~cm}^{-1}$ (Tab. 21) which accounts for $535 \mathrm{~cm}^{-1}$ (Tab. 12) bathochromic shift, $230 \%$ of the experimental value (please note, the vacuum theoretical estimate and, of course, hydrated experimental values are compared). The $\kappa^{12} \operatorname{co} 5$ prediction is even more deviated.

As a substitute, we can discuss the decrease of the vertical excitation energy $T_{e}$ with the respect to (sulphate, selenate) ligand coordination-then the predicted bathochromic shift of $T_{e}$ is at least $560 \mathrm{~cm}^{-1}$ (for 10 solvating water molecules, Tab. 15, Tab. 19), as compared to $140 \mathrm{~cm}^{-1}$ for $T_{0-0}$ experimentally determined change. From Tab. 15 and Tab. 22 we can also deduce the bathochromic shift (i.e. lowering) of $T_{e}$ in comparison $\left[\mathrm{UO}_{2}\left(\mathrm{\kappa}^{2}-\mathrm{SO}_{4}\right)_{3}\right]^{4} \cdot 30 \mathrm{H}_{2} \mathrm{O}$ and $\left[\mathrm{UO}_{2}\left(\mathrm{H}_{2} \mathrm{O}\right)_{5}\right]^{2+} \cdot 20 \mathrm{H}_{2} \mathrm{O}$. Te of the former is by $327 \mathrm{~cm}^{-1}$ lower.

Explanation of the predicted unrealistically high bathochromic shifts might be that sulphate coordinated species, in particular those with negative net charge, have loosely bounded LUMO electrons. Better chosen atomic basis set should be used to describe them.

The vibrational frequency of $\kappa^{2} \cos$ uranyl monosulphate isomer $\left(\left[\mathrm{UO}_{2}\left(\kappa^{2}-\mathrm{SO}_{4}\right)\left(\mathrm{H}_{2} \mathrm{O}\right)_{3}\right] \cdot n \mathrm{H}_{2} \mathrm{O}\right)$ with $n=10$ water molecule, $909 \mathrm{~cm}^{-1}$ (Tab. 19), is by $18 \mathrm{~cm}^{-1}$ lower than the corresponding quantity for $\left[\mathrm{UO}_{2}\left(\mathrm{H}_{2} \mathrm{O}\right)_{5}\right]^{2+}$ $\left(927 \mathrm{~cm}^{-1}\right.$, Tab. 10).

For 30 water molecules surrounded uranyl tris (sulphate), the vibrational frequency has been determined as $879 \mathrm{~cm}^{-1}$ (Tab. 22), lower by $15 \mathrm{~cm}^{-1}$ than $\omega_{g s}$ for $\left[\mathrm{UO}_{2}\left(\mathrm{H}_{2} \mathrm{O}\right)_{5}\right]^{2+} \cdot 20 \mathrm{H}_{2} \mathrm{O}$ (Tab.10).

For uranyl - selenate system, even greater difficulties have been met. With predicted Te for bis(selenate) being greater than for monoselenate) and similar anomalies. The

\footnotetext{
${ }^{\text {tt }}$ Which will be placed on the first author's Academia.edu personal page in next weeks.
}

detailed report will be given in the Supplementary Information.

CIS (with HF as ground-state reference) method has been shown as unfeasible for spectroscopic properties predictions. CIS(D), on the other side, might be interesting for comparison (and we will aim to apply CC-family methods as well) (Tab. 12).

The peak full-width-half-maxima (FWHM) can be explained and modelled by $T_{0-0}$ and $\omega_{g s} /$ Franck-Condon factor calculations based on (Maxwell-Boltzmann-factorweighted average of) different PES local minima, isomers and solvation surroundings. Of course, another potential source of band-width is theoretical possibility for transitions from another electronic excited states quasidegenerate with the lowest lying one (see the chapter 2.1 and the Supplementary Information ${ }^{\text {tt }}$ )

Important would be to estimate spectral norms, $\mathrm{mm}$ and therefore absorption and luminescence full, not normalized, spectra. For this purpose, however, spinorbital interaction is essential. In best case, the fourcomponent Dirac-Coulomb-Gaunt Hamiltonian and wavefunctions should be used. The electronic transition probability between the excited $\Omega=1_{\mathrm{g}}$ state, which is superposition of several spin-multiplicity components (let us denote the corresponding coefficients as $c(1 \mathrm{~g}, 2 \mathrm{~s}+1))$,

$$
\begin{aligned}
& \left|1_{g}\right\rangle=\sum_{s=0}^{s_{\max }} c\left(1_{g}, 2 s+1\right)\left|{ }^{2 s+1} Y_{e s}\right\rangle, \\
& \left.\left|0_{g}^{+}\right\rangle=\left.\sum_{s=0}^{s_{\max }} c\left(0_{g}^{+}, 2 s+1\right)\right|^{2 s+1} Y_{g s}\right\rangle,
\end{aligned}
$$

similarly for the ground state $\Omega=0_{\mathrm{g}}{ }^{+}$. We suppose that the ground state is dominated by the singlet component and excited state by a triplet component. The radiational transition probability $1_{\mathrm{g}} \rightarrow 0_{\mathrm{g}}{ }^{+}$is then given by formula

$$
\begin{aligned}
& P\left(1_{g} \rightarrow 0_{g}^{+}\right)= \\
& \sum_{s=0}^{s_{\max }}\left|c\left(0_{g}^{+}, 2 s+1\right)\right|^{2}\left|c\left(1_{g}, 2 s+1\right)\right|^{2}\left|\left\langle{ }^{2 s+1} Y_{e s}|\hat{T}|^{2 s+1} Y_{g s}\right\rangle\right|^{2},
\end{aligned}
$$

where terms in the summation corresponds to singletsinglet, triplet-triplet, quintuplet-quintuplet, ... transitions between hypothetical eigenstates of total molecular spin. The matrix elements correspond to $\Delta L_{z}= \pm 1$ dipole transitions.

We hope that the contribution presented can serve as a good methodological base for further, more accurate, theoretical predictions of uranyl (VI) complex species spectroscopic and thermodynamic properties.

\section{Acknowledgements}

I would like to thank the Department of Nuclear Chemistry for support. the Czech Student Grant Agency (grant no. SGS16/250/OHK4/3T/14) for material support. Special thanks are for experimental collaborators - Bc. Jakub Kuba. Dr. Vladimir Sladkov and Dr. Aleš Vetešník. Useful 
help and hints came from Dr. Šebesta, Fibich and Sláma. I would like to thank TESNAT 2016 Organizing Committee for hospitality and the opportunity to present my work. Access to computing and storage facilities: National Grid Infrastructure MetaCentrum (www.metacentrum.cz). under program CESNET LM2015042 is greatly appreciated.

\section{References}

1. R.J. Lakowicz, Principles of Fluorescence Spectroscopy, Springer, (2006).

2. G. Meinrath, Review Focusing on Aspects of Environmental Chemistry, (1998).

3. http://www.world-nuclear.org

4. W.G. Wright, J. Environ. Qual., 28, No 4 (1999).

5. D. Vopálka, et al., J. Radioanal. Nucl. Chem., 286: 681 (2010).

6. A. Vetešník, et al., Uranium, Mining and Hydrogeolology. Springer, p. 623-630. (2008).

7. J. Višňák, et al., The New Uranium Mining Boom, Edts: B. Merkel and M. Schipek, 643-652 (2012).

8. T. Vercouter, P. Vitorge, B. Amekraz, Ch. Moulin, Inorg. Chem., 47, 2180-2189 (2008).

9. V. Sladkov, B. Fourest, F. Mercier, Dalton Trans., 7734-7740 (2009).

10. P. Lubal, J. Havel, Chem. Papers 51 (4) 213-220 (1997).

11. P. Lubal, J. Havel, Talanta 44, 457-466 (1997).

12. M. Maeder, Y.-M. Neuhold, Science and Technology, Edt: S. Rutan and B. Walczak, 26, Elsevier, (2007).

13. J. Višňák, Master Thesis, FNSPE, Czech Technical University (2010) (In Czech).

14. A. de Juan, R. Tauler, Anal. Chim. Acta, 500 (1-2): 195-210 (2003).

15. R. Bro, et al., Applied Spectroscopy Reviews. 32 (3): 237-261 (1997).

16. Ch. F. Beckmann, S.M. Smith, Tensorial Extensions of Independent Component Analysis for MultiSubject FMRI Analysis, FMRIB, Technical Report TR04CB1, http://www.fmrib.ox.ac.uk.

17. R. Harshman, M. Lundy, Research methods for multimode data analysis, 122-215. Praeger, (1984).

18. R. Harshman, UCLA Working Papers in Phonetics, 16, 84 pp. (1970).

19. G.H. Golub, C. Reinsch, Numerische Mathematik. 14 (5): 403-420, (1970).

20. P. Atkins, J. De Paula, Physical Chemistry, W.H. Freeman and Company. p. 212 (2006).

21. K.G. Dyall, K. Jr. Faegri, Introduction to Relativistic Quantum Chemistry, Oxford Uni. Press, (2007).

22. P. Hohenberg, W. Kohn, Phys. Rev. 136 (3B): B864B871, (1964).

23. W. Kohn, L.J. Sham, Phys. Rev. 140 (4A): A1133A1138 (1965).

24. A. Szabo, N.S. Ostlund, Modern Quantum Chemistry: Introduction to Advanced Electronic Structure Theory, McGraw-Hill, (1989).

uu The formula on the respective page 1941 there contains, however error/typo, the correct one should read
25. E. Runge, E.K.U. Gross, Phys. Rev. Lett. 52 (12): 997-1000 (1984).

26. M. Petersilka, U.J. Gossmann; E.K.U. Gross, Phys. Rev. Lett. 76 (8): 1212-1215 (1996).

27. C. Ullrich, Time-Dependent Density-Functional Theory: Concepts and Applications, Oxford University, (2012).

28. A.D. Becke, J. Chem. Phys. 98 (7): 5648-5652 (1993).

29. F. Weigend et al, Chem. Phys. Letters 294, 143 (1998).

30. TURBOMOLE V6.5 2013, University of Karlsruhe and Forschungszentrum Karlsruhe GmbH, 19892007, http://www.turbomole.com.

31. F. Furche, et al., WIREs Comput Mol Sci, 4:91-100 (2014).

32. X. Cao, M. Dolg, J. Molec. Struct., 673, 203-209 (2004).

33. M. Dolg, in Proceedings, J. Grotendorst (Ed.), John von Neumann Institute for Computing, 3, pp. 507-540 (2000).

34. V.E. Jackson, et al., J. Phys. Chem. A, 112, $4095-$ 4099, (2008).

35. Z. Wang, et al., Environ. Sci. Technol., 38, 5591-5597 (2004).

36. J. Višňák, J et al., In Lectures of colloquium on Radioanalytical methods, IAA 14, (2014).

37. J. T. Bell, R.E. Biggers, J. Molecular Spectroscopy, 25, 312 (1986).

38. L.H. Jones, Spectrochim. Acta, 10, 395-403, (1958).

39. J.J. Olivero, R.L. Longbothum, J. of Quantitative Spectroscopy and Radiative Transfer. 17 (2): 233-236 (1977).

40. G.K. Wertheim, et al., Review of Scientific Instruments. 45 (11): 1369-1371 (1974).

41. M. Gal, P.L. Goggin, J. Mink, Spectrochim. Acta 48A (1992).

42. L.C. Andrews, Special Functions of Mathematics for Engineers, Oxford Science Publications, (1998).

43. W.H. Greene, Econometric Analysis, Prentice-Hall, (1993).

44. M. Born, R. Oppenheimer, Ann. Phys. 84, 457 (1927).

45. J. Franck, Transactions of the Faraday Society, 21: 536-542, (1926).

46. E. Condon, Phys Rev, 28: 1182-1201, (1926).

47. A.S. Coolidge, H.M. James, R.D. Present, J. Chem. Phys, 4: 193-211, (1936).

48. P.W. Atkins, R.S. Friedman, Molecular Quantum Mechanics, Oxford University Press, (1999).

49. V.I. Minkin, Pure and Applied Chemistry. 71, 10, Pages 1919-1981. uu

50. E. Rudberg, Diploma work in Physical Chemistry, Royal Institute of Technology, Sweden (2003).

51. M. Abramowitz, I. A. Stegun, eds. "Chapter 22". Handbook of Mathematical Functions with Formulas, Graphs, and Mathematical Tables. Applied Mathematics Series. 55 Dover Publications. (1983).

52. https://en.wikipedia.org/wiki/Hermite polynomials

$$
V=\frac{1}{2} \sum_{i, j=1}^{3 N} \frac{\partial^{2} V}{\partial q_{i} \partial q_{j}} q_{i} q_{j}
$$


53. J. Višňák routine in Wolfram Mathematica [54].

54. Wolfram Research, Inc., Mathematica, Version 10.4, Champaign, IL (2016).

55. J.D.J. Ingle, S.R. Crouch, Spectrochemical Analysis, Prentice Hall, (1988).

56. J.-L. Chang, J. Mol. Spectrosc., 232, 102-104, (2005).

57. R. Islampour, et al., J. Mol. Spectrosc. 194, 179-184 (1999).

58. P.-A. Malmqvist, N. Forsberg, Chem. Phys., 228, 227-240, (1998).

59. K. Pierloot K., E. van Besien, J Chem Phys 123, 204309 (2005).

60. J. Mehra, H. Rechenberg, The Historical Development of Quantum Theory, Springer, 2001.

61. G. Budylin, et al., Optics Express, 21, No. 18, (2013).

62. H. D. Burrows, S. J. Formosinho, J. Chem. Educ., 55 (2), p 125 (1978).

63. Laser-Induced Spectroscopy, Helmholtz Zentrum Dresden Rossendorf website, http://www.hzdr.de.

64. H.T. Evans Jr., Science, 141, 154-158, (1963).

65. R.G. Denning, Gmelin Handbuch der Anorganischen Chemie, Uran (Supplement) A6, 31-79, (1983).

66. R.G. Denning, et al., Mol. Phys., 37, 1089 - 1107, (1979).

67. B. Zhu, S.A. Pennell, D.K. Ryan, Microchem. J., 115, 51-57, (2014).

68. C. Hennig, et al., AIP Conf. Proc., 882, 262 (2007).

69. J. Šebera et al, In Scientific report of the project for SÚRAO, the Czech Radioactive Waste Repository Authority for the final control date (Phase 4), FNSPE, Czech Technical University, p 27-42, (July 2009).

70. J.N. Brønsted, J. Am. Chem. Soc., 44, 877-898 and 938-948 (1922).

71. G. Scatchard, Chem. Rev., 19, 309-327 (1936).

72. E.A. Guggenheim, Applications of Statistical Mechanics, Clarendon Press, (1966).

73. M.R. Wright, An Introduction to Aqueous Electrolyte Solutions, section 10.6.15, Wiley, (2007).

74. I. Grenthe, H. Wanner, E. Osthols, $T D B-2$, Guidelines for the extrapolation to zero ionic strength, OECD Nuclear Energy Agency, (2000).

75. M. Bühl, et al., Inorg. Chem., 50, 299-308 (2011).

76. M. Zhou, L. Andrews, N. Ismail, C. Marsden, J. Phys. Chem. A, 104, 5495-5502 (2000).

77. W.A. Gezahegne, et al., Environ. Sci. Technol., 46, 2228-2233 (2012).

78. B. Li, et al., Comp. Theor. Chem., 1051, 151-160, (2015).

79. L. Gagliardi, et al., J. Phys. Chem. A, 105, 1060210606, (2001).

80. P.D. Dau, et al., J. Chem. Phys., 137, 064315 (2012).

81. M. Head-Gordon, et al., Chem. Phys. Lett. 219, 21 (1994).

82. P.A.M. Dirac, Proc. Royal Soc. (London) A, 123, 714, (1929).

83. J.C. Slater, Phys. Rev., 81, 385, (1951).

84. S.H. Vosko, L. Wilk, M. Nusair, Can. J. Phys., 58 1200, (1980).

85. C. Lee, W. Yang, R.G. Parr, Phys. Rev. B, 37, 785 (1988).

86. A.D. Becke, Phys. Rev. A 38, 3098 (1988).

87. J.P. Perdew, Phys. Rev. B 33, 8822 (1986).
88. DIRAC, a relativistic ab initio electronic structure program, Release DIRAC13 (2013), written by L. Visscher, et al.

89. A. Schäfer, et al., Phys. Chem. Chem. Phys., 2, $2187-$ 2193, (2000).

90. K. Eichkorn, et al., Chem. Phys. Letters 242, 652 (1995).

91. K. Eichkorn, et al., Theor. Chem. Acc. 97, 119 (1997).

92. M. Sierka, A. Hogekamp and R. Ahlrichs; J. Chem. Phys. 118, 9136, (2003).

93. S. Grimme, J. Antony, S. Ehrlich, Krieg, J. Chem. Phys, 132, 154104 (2010).

94. E.B. Wilson, Jr., J. Chem. Phys. 9 (1): 76-84 (1941).

95. A. Malijevksý, University of Chemistry and Technology, Prague, 2009. http://old.vscht.cz.

96. J. Višñák, et al., Annual report of the Department of Nuclear Chemistry 2011-2012, Prague. http://www.jaderna-chemie.cz/data.

97. J. Višňák, et al., Annual report of the Department of Nuclear Chemistry 2008-2010, Prague. http://www.jaderna-chemie.cz.

98. J. Višňák, Laserem indukovaná fluorescenční spektroskopie s časovým rozlišením jako nástroj pro př́mou speciaci uranu o nízkých koncentracích, Bachelor project, FNSPE, Czech Technical University in Prague (2008).

99. V. Sladkov, J. Chromatography A, 1276, 120-125, (2013).

100.A. Schäfer, J. Chem. Phys., 97, 2571 (1992).

101.A.S.P. Gomes, K.G. Dyall, L. Visscher, Theor Chem Acc, 127: 369, (2010).

102. J.M. Martinez, L. Martinez, J. Comput. Chem., 24:819-825,(2003).

103.A.K. Rappé, et al., J. Am. Chem. Soc., 114(25), 10024-10035, (1992).

104.G.Schaftenaar and J.H. Noordik, J. Comput.-Aided Mol. Design, 14, 123-134, (2000).

105. MATLAB and Statistics Toolbox Release 2012b, The MathWorks, United States.

106.B. Drobot, et al., Chem. Sci., 6, 964-972, (2015). 